Key Words:

Antifoam

KTPB

STTPB

Retention:

Permanent

\title{
LABORATORY SCALE ANTIFOAM STUDIES FOR THE STTPB PROCESS (U)
}

\author{
M. A. Baich \\ D. P. Lambert \\ P. R. Monson
}

OCTOBER 24, 2000

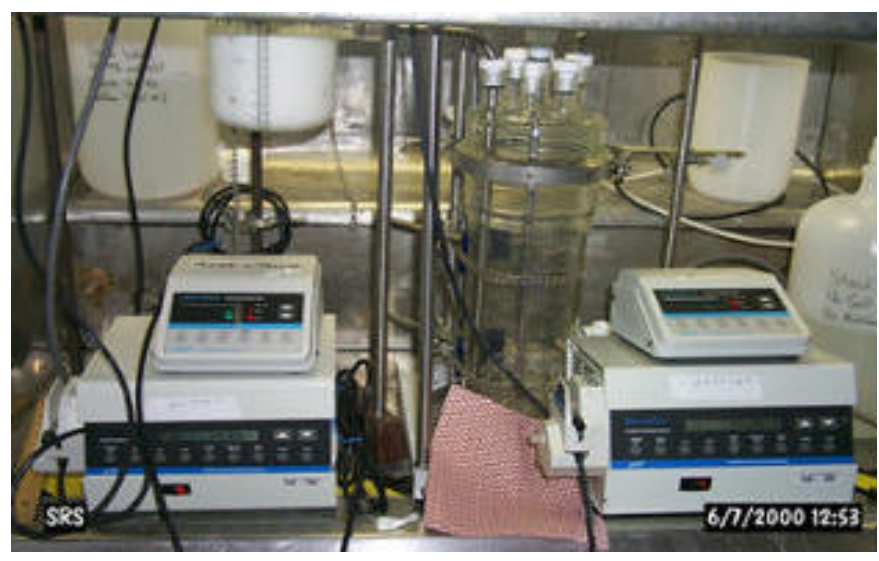

Westinghouse Savannah River Company

Savannah River Site

Aiken, SC 29808

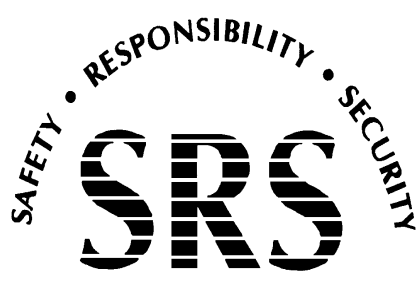


This document was prepared in conjunction with work accomplished under Contract No.

DE-AC09-96SR18500 with the U.S. Department of Energy.

\section{DISCLAIMER}

This report was prepared as an account of work sponsored by an agency of the United States Government. Neither the United States Government nor any agency thereof, nor any of their employees, makes any warranty, express or implied, or assumes any legal liability or responsibility for the accuracy, completeness, or usefulness of any information, apparatus, product or process disclosed, or represents that its use would not infringe privately owned rights. Reference herein to any specific commercial product, process or service by trade name, trademark, manufacturer, or otherwise does not necessarily constitute or imply its endorsement, recommendation, or favoring by the United States Government or any agency

thereof. The views and opinions of authors expressed herein do not necessarily state or reflect those of the United States Government or any agency thereof.

This report has been reproduced directly from the best available copy.

Available for sale to the public, in paper, from: U.S. Department of Commerce, National Technical Information Service, 5285 Port Royal Road, Springfield, VA 22161, phone: (800)

553-6847, fax: (703) 605-6900, email: orders@ntis.fedworld.gov online ordering: http://www.ntis.gov/ordering.htm

Available electronically at http://www.doe.gov/bridge

Available for a processing fee to U.S. Department of Energy and its contractors, in paper, from: U.S. Department of Energy, Office of Scientific and Technical Information, P.O. Box 62, Oak Ridge, TN 37831-0062, phone: (865 ) 576-8401, fax: (865) 576-5728, email: reports@ adonis.osti.gov 
Key Words:

Antifoam

KTPB

STTPB

Retention:

Permanent

\title{
LABORATORY SCALE ANTIFOAM STUDIES FOR THE STTPB PROCESS (U)
}

\author{
M. A. Baich \\ D. P. Lambert \\ P. R. Monson
}

OCTOBER 24, 2000

Westinghouse Savannah River Company

Savannah River Site

Aiken, SC 29808

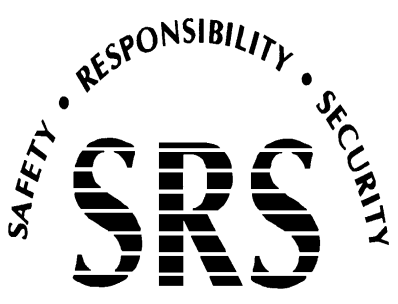

SAVANNAH RIVER SITE 


\section{REVIEWS AND APPROVALS}

M. A. Baich, Co-Author, Immobilization Technology

Date

D. P. Lambert, Co-Author, Immobilization Technology

Date

P. R. Monson, Co-Author, Immobilization Technology

Date

R. E. Eibling, Peer Reviewer, Immobilization Technology

Date

L. F. Landon, Manager, Process Development

Date

J. T. Carter, Manager, HLW Process Engineering

Date

K. J. Rueter, Director of Salt Disposition Engineering

Date

W. L. Tamosaitis, Manager, Waste Processing Technology

Date

J. F. Walker, TFA System Lead

Date

Page ii 


\section{TABLE OF CONTENTS}

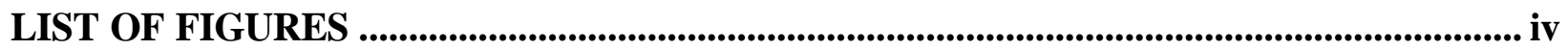

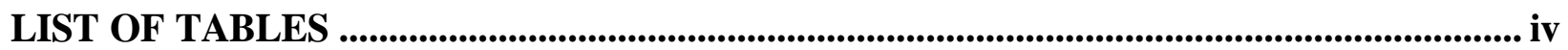

LIST OF ACRONYMS .............................................................................................................. iv

1.0 EXECUTIVE SUMMARY............................................................................................................ 1

2.0 INTRODUCTION.................................................................................................................... 1

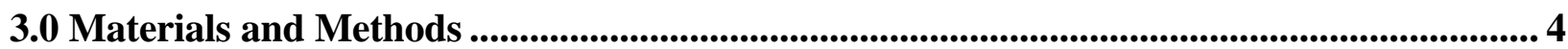

3.1 Composition of Salt Solution Simulant.......................................................................................... 4

3.2 Experimental Equipment ................................................................................................................... 4

3.2.1 Precipitation Process.................................................................................................................... 4

3.2.2 Concentration and Washing Processes ......................................................................................... 6

4.0 Description of Experiments and Results ......................................................................................... 9

4.1 Precipitation Step.................................................................................................................................. 9

4.1.1 No Antifoam Baseline ................................................................................................................... 9

4.1.2 IIT B52 Antifoam Test................................................................................................... 10

4.1.3 IIT PM Antifoam Test........................................................................................................ 11

4.1.4 Surfynol DF-110D Defoamer Test......................................................................................... 11

4.2 Concentration Step..................................................................................................................... 12

4.2.1 No Antifoam Baseline .............................................................................................. 12

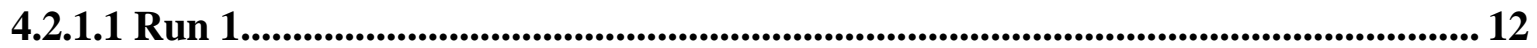

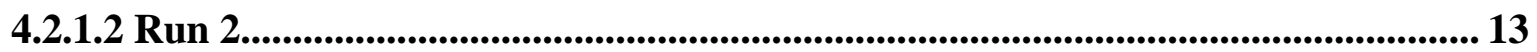

4.2.2 IIT B52 Antifoam Test....................................................................................................... 14

4.2.3 IIT PM Antifoam Test................................................................................................. 14

4.2.4 Surfynol DF-110D Test........................................................................................................... 14

4.3 Precipitate Washing Cycle ........................................................................................................... 15

4.3.1 No Antifoam Baseline .............................................................................................................. 15

4.3.2 IIT B52 Antifoam Test........................................................................................................... 17

4.3.3 IIT PM Antifoam Test............................................................................................................ 19

4.3.4 Surfynol DF-110D Test...................................................................................................... 22

4.4 Rheological Properties Of Product Slurries........................................................................... 24

4.5 Foam Column Tests......................................................................................................................... 25

4.5.1 Testing Protocol and Results ............................................................................................... 27

4.5.2 Antifoam Effectiveness During Testing ..........................................................................29

4.6 Solubility Study of Candidate Antifoam/Defoam Agents .................................................31

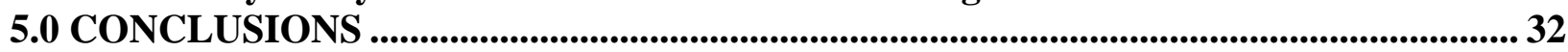

6.0 FUTURE WORK ................................................................................................................................... 33

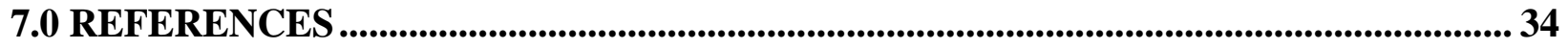

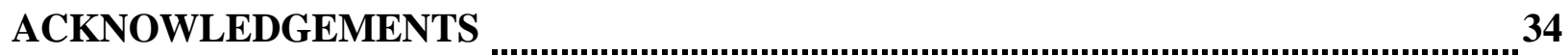

APPENDIX A 


\section{LIST OF FIGURES}

Figure 1 Schematic and Table Summarizing Streams to the STTPB Process. ${ }^{2}$ ….................... 3

Figure 2 Schematic of Dual CSTR Precipitation System................................................................5

Figure 3 Sketch of the Concentration/Wash Vessel............................................................................ 7

Figure 4 Schematic of Concentration and Washing Apparatus ...................................................... 8

Figure 5 Nitrite Profile for the No Antifoam Washing Cycle ........................................................ 16

Figure 6 NaTPB Profile for No Antifoam Washing Cycle ............................................................. 17

Figure 7 Nitrite Profile for the IIT B52 Antifoam Washing Cycle............................................. 18

Figure 8 NaTPB Profile for the IIT B52 Antifoam Washing Cycle ............................................ 19

Figure 9 Nitrite Profile During IIT PM Antifoam Washing .......................................................... 21

Figure 10 NaTPB Profile for the IIT PM Antifoam Washing Cycle......................................... 22

Figure 11 Nitrite Profile for the Surfynol DF 110D Antifoam Washing Cycle ....................... 23

Figure 12 NaTPB Profile for the Surfynol DF 110D Antifoam Washing Cycle...................... 24

Figure 13. Rheological Increasing Shear Rate Flow Curves for Product Slurries................. 25

Figure 14 Schematic of the Foam Column Apparatus ...................................................................26

Figure 15 Large Foam Column Test \#1 ............................................................................................... 28

Figure 16 Large Foam Column Test \# 2 .......................................................................................... 29

Figure 17 Large Foam Column Test \#3 .................................................................................. 29

\section{LIST OF TABLES}

Table 1 Composition for 1 Liter of 9.4 M Na Salt Solution Simulant .......................................... 4

Table 2 Result of Large Foam Column Tests..................................................................................... 28

Table 3 Solubility of Candidate Antifoams/Defoams ...................................................................... 32

\section{LIST OF ACRONYMS}

KTPB Potassium Tetraphenylborate

NaTPB Sodium Tetraphenylborate

STTPB Small Tank Tetraphenylborate Process

IIT B52 A proprietary antifoam agent prepared by Illinois Institute of Technology under contract to WSRC.

IIT PM A proprietary particle modifier antifoam agent prepared by Illinois Institute of Technology under contract to WSRC.

MST Monosodium titanate

Surfynol DF-110D A Diol based defoaming agent produced by Air Products \& Chemical Company 
WSRC-TR-2000-00261, REVISION 0

\subsection{EXECUTIVE SUMMARY}

Three candidate antifoam/defoam agents were tested on a laboratory scale with simulated KTPB slurry using the proposed STTPB process precipitation, concentration and washing steps. In all cases, little or no foam formed during normal operations of precipitation, concentration and washing. Foam was produced by purposely introducing gas sub-surface into the slurry. Once produced, the IIT B52 antifoam was effective in defoaming the slurry.

In separate foam column tests, all three antifoam/defoam agents were effective in mitigating foam formation and in defoaming a foamed $10 \mathrm{wt} \%$ unwashed insoluble solids slurry. In our initial testing in a 1" diameter foam column, the B52 antifoam was ineffective but upon retesting with a new shipment of the same Lot\# of B52 antifoam in a larger 2.5" diameter foam column, B52 was clearly the superior agent as both a defoamer and an antifoamer. Based on the results in this report, as well as foam column studies at IIT ${ }^{1}$, it is recommended that IIT B52 antifoam at the $1000 \mathrm{ppmV}$ level be used in subsequent STTPB work where foaming is a concern. The loss of effectiveness of the original B52 antifoam could have been due to degradation or contamination. Periodic testing of antifoam effectiveness is warranted.

The presence of the three antifoam agents appears to hinder the effectiveness in washing excess NaTPB from the concentrated slurry to varying degrees. The most effective antifoam (B52) produced the greatest decline in the NaTPB recovery during washing. Nitrite washing does not appear to be affected by the presence of antifoam agent. The rheological properties; consistency and yield stress of the product slurries were reduced by the presence of antifoam agents.

The solubilities of the three candidate antifoam/defoam agents were measured in a $4.7 \mathrm{M}$ sodium salt solution. The Surfynol DF-110D defoamer was essentially insoluble while the two IIT antifoamers; Particle Modifier (PM) and B52 were soluble to at least the $2000 \mathrm{ppmV}$ level.

\subsection{INTRODUCTION}

One of the alternatives to processing the highly radioactive salt solutions in the SRS Waste Tanks is to precipitate the highly radioactive cesium with sodium tetraphenylborate and then concentrate and wash the precipitate slurry. Hydrolysis will be done in a new Salt Disposition Facility prior to subsequent processing in the Defense Waste Processing Facility (DWPF). This alternative salt disposition process is called the Small Tank Tetraphenylborate Precipitation process (STTPB). In the STTPB precipitation process, soluble ions of cesium, potassium and ammonium are precipitated as insoluble TPB (tetraphenylborate) salts. Strontium, uranium, and plutonium are sorbed on solid monosodium titanate (MST). The resulting slurry, which now contains most of the radionuclides as insoluble solids, is filtered to concentrate the solids. After washing the solids to reduce the concentration of soluble sodium salts in the slurry, the precipitate is processed in the Salt Disposition Facility and

Page 1 of 34 
incorporated into glass in the DWPF. The decontaminated salt solution or filtrate is transferred to Z Area for processing and disposal as Saltstone. ${ }^{2}$

Figure 1 below is a schematic of the STTPB process with projected full-scale plant flows. The initial salt solution, $6.44 \mathrm{M}$ in $\mathrm{Na}$ (from tank 48 or $9.4 \mathrm{M} \mathrm{Na}$ representing a composite of tanks as reported by Peterson in reference 3), is fed continuously into CSTR \#1 along with the volume of process water necessary to carry out the precipitation at the optimum concentration of 4.7 M Na. Recycle wash water, MST and NaTPB solution (60\% excess TPB) is also continuously fed into CSTR \#1. The precipitate slurry continuously overflows to a second identical CSTR \#2, which serves to increase the residence time for the precipitation process to 16-24 hours. The precipitation process is rapid. The rate determining step is the adsorption of the plutonium, uranium and strontium on the MST solids. The slurry exiting CSTR \#2 is 0.5$1.0 \mathrm{wt} \%$ insoluble solids and is concentrated through a crossflow filter in the concentrate tank to about $10 \mathrm{wt} \%$ insoluble solids. The concentrated slurry is then washed with dilute caustic $(0.01 \mathrm{M})$ using a crossflow filter to (1) reduce the nitrite to $\leq 0.01 \mathrm{M}$ for Precipitate Hydrolysis processing, (2) reduce the $\mathrm{Na}$ concentration to a level acceptable for glass production and (3) recover a portion of the excess NaTPB for recycle to CSTR \#1.

In recent tests of the precipitation process using actual radioactive waste material excessive foaming was observed. ${ }^{3}$ Foaming was also observed in testing at ORNL using slurry spiked with radioactive cesium. ${ }^{4}$ Foaming during the precipitation, concentration and washing steps using simulants was also observed at SRTC. ${ }^{5}$ As a result of these experiences with foam generation during proposed STTPB process steps, an investigation into finding suitable antifoam/defoam agents that can eliminate or mitigate the consequences of foam generation during normal operations of the proposed STTPB process was undertaken.

Antifoam experts at IIT (Drs. D. T. Wasan and A. D. Nikolov) were contracted (Contract \# AE-14869S) to develop and recommend three potential antifoam/defoam agents to be tested in laboratory scale demonstrations of the precipitation, concentration and washing steps using simulated waste.

This report describes these tests using the commercially available defoamer Surfynol ${ }^{\circledR}$ DF110D and two proprietary antifoam agents developed by IIT called Particle Modifier (IIT PM) and B52 (IIT B52). The Particle Modifier acts as an antifoam and the B52 has dual properties as a defoamer and an antifoamer. During testing at IIT, Surfynol DF-110L was used and recommended instead of Surfynol DF-110D as was used in this study. 


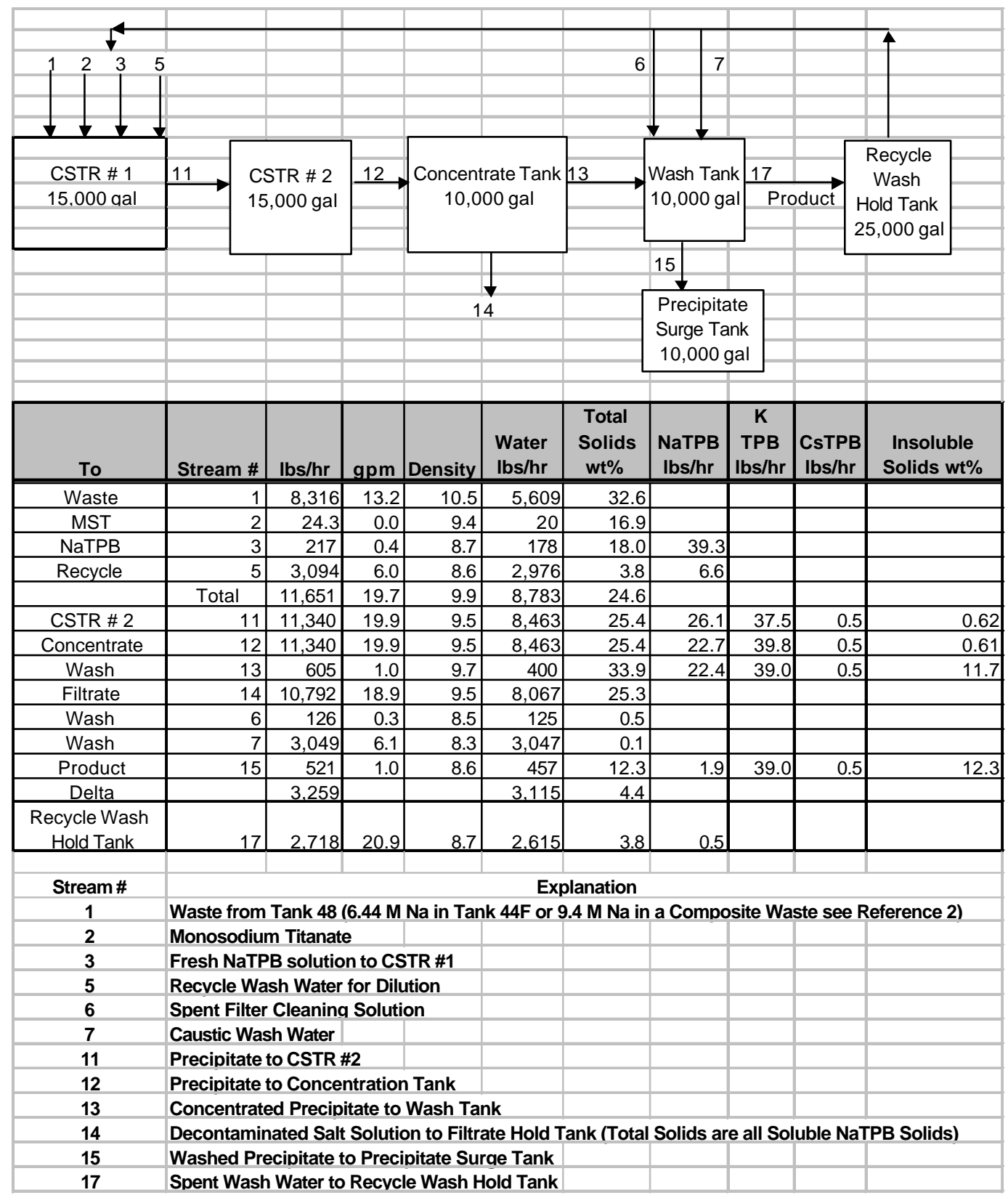

Since the present work began a higher production rate of $17.561 \mathrm{gpm}$ versus $13.2 \mathrm{gpm}$

has been achieved. This table reflects the lower production rate.

Figure 1 Schematic and Table Summarizing Streams to the STTPB Process. ${ }^{2}$ 
WSRC-TR-2000-00261, REVISION 0

\subsection{MATERIALS AND METHODS}

\subsection{COMPOSITION OF SALT SOLUTION SIMULANTS.}

A stock solution of 9.4 M Na salt solution was prepared as the starting salt solution simulating a composite of the high sodium HLW salt solution coming into CSTR \#1 in the precipitation process. The precipitation was carried out in a $4.7 \mathrm{M} \mathrm{Na}$ salt solution. Table 1 gives the typical composition of this salt solution. Four identical 20-liter batches of this salt solution were made. One 20-L batch for each of the four test precipitations: (1) No Antifoam, (2) IIT B52 antifoam, (3) IIT PM Antifoam and (4) Surfynol ${ }^{\circledR}$ DF-110D.

Table 1 Composition for 1 Liter of 9.4 M Na Salt Solution Simulant

\begin{tabular}{|l|c|c|c|}
\hline \multicolumn{1}{|c|}{ Compound } & Conc. $(\mathbf{M})$ & $\mathbf{N a}^{+} \mathbf{M}$ & Grams \\
\hline $\mathrm{NaOH}$ & 5.28 & 5.28 & 211.500 \\
\hline $\mathrm{NaNO}_{3}$ & 2.00 & 2.00 & 170.481 \\
\hline $\mathrm{NaNO}_{2}$ & 0.87 & 0.87 & 60.227 \\
\hline $\left.\mathrm{Al}_{2} \mathrm{NO}_{3}\right)_{3} \cdot 9 \mathrm{H}_{2} \mathrm{O}$ & 0.52 & & 195.186 \\
\hline $\mathrm{Na}_{2} \mathrm{CO}_{3}$ & 0.27 & 0.54 & 28.468 \\
\hline $\mathrm{Na}_{2} \mathrm{SO}_{4}$ & 0.25 & 0.50 & 35.754 \\
\hline $\mathrm{NaCl}$ & 0.04 & 0.04 & 2.452 \\
\hline $\mathrm{NaF}$ & 0.05 & 0.05 & 2.256 \\
\hline $\mathrm{Na}_{3} \mathrm{PO}_{4} \cdot 12 \mathrm{H}_{2} \mathrm{O}$ & 0.017 & 0.05 & 6.177 \\
\hline $\mathrm{Na}_{2} \mathrm{C}_{2} \mathrm{O}_{4}$ & 0.013 & 0.026 & 1.800 \\
\hline $\mathrm{Na}_{2} \mathrm{SiO}_{3} \cdot 9 \mathrm{H}_{2} \mathrm{O}$ & 0.007 & 0.014 & 1.908 \\
\hline $\mathrm{Na}_{2} \mathrm{MoO}_{4} \cdot 2 \mathrm{H}_{2} \mathrm{O}$ & 0.0003 & 0.0006 & 0.094 \\
\hline $\mathrm{KNO}_{3}$ & 0.025 & & 2.546 \\
\hline $\mathrm{CsNO}_{3}$ & 0.0002 & & 0.046 \\
\hline $\mathrm{DI} \mathrm{H}_{2} \mathrm{O}$ & & & 654.75 \\
\hline $\mathrm{Total}$ & & 9.37 & \\
\hline
\end{tabular}

The precipitant solution was a combination of the recycle stream, the NaTPB stream, and the monosodium titanate (MST) adsorbent. The NaTPB solution was $0.55 \mathrm{M}$ in NaTPB in $0.1 \mathrm{M}$ $\mathrm{NaOH}$. The MST was added as a solid at $0.51 \mathrm{~g} / \mathrm{L}$ of the precipitant solution.

\subsection{EXPERIMENTAL EQUIPMENT}

\subsubsection{Precipitation Process}

To simulate the precipitation process, two identical 4-L glass CSTR's were fabricated in the SRTC Glass Shop. These two vessels had a sidearm at about the 1.5-L level to allow slurry from CSTR \#1 to overflow into CSTR \#2 and then CSTR \#2 overflow into a collection tank. 
The vessels had the capacity to contain a foam level of at least $400 \%$. A schematic of the precipitation vessels is show if Figure 2.

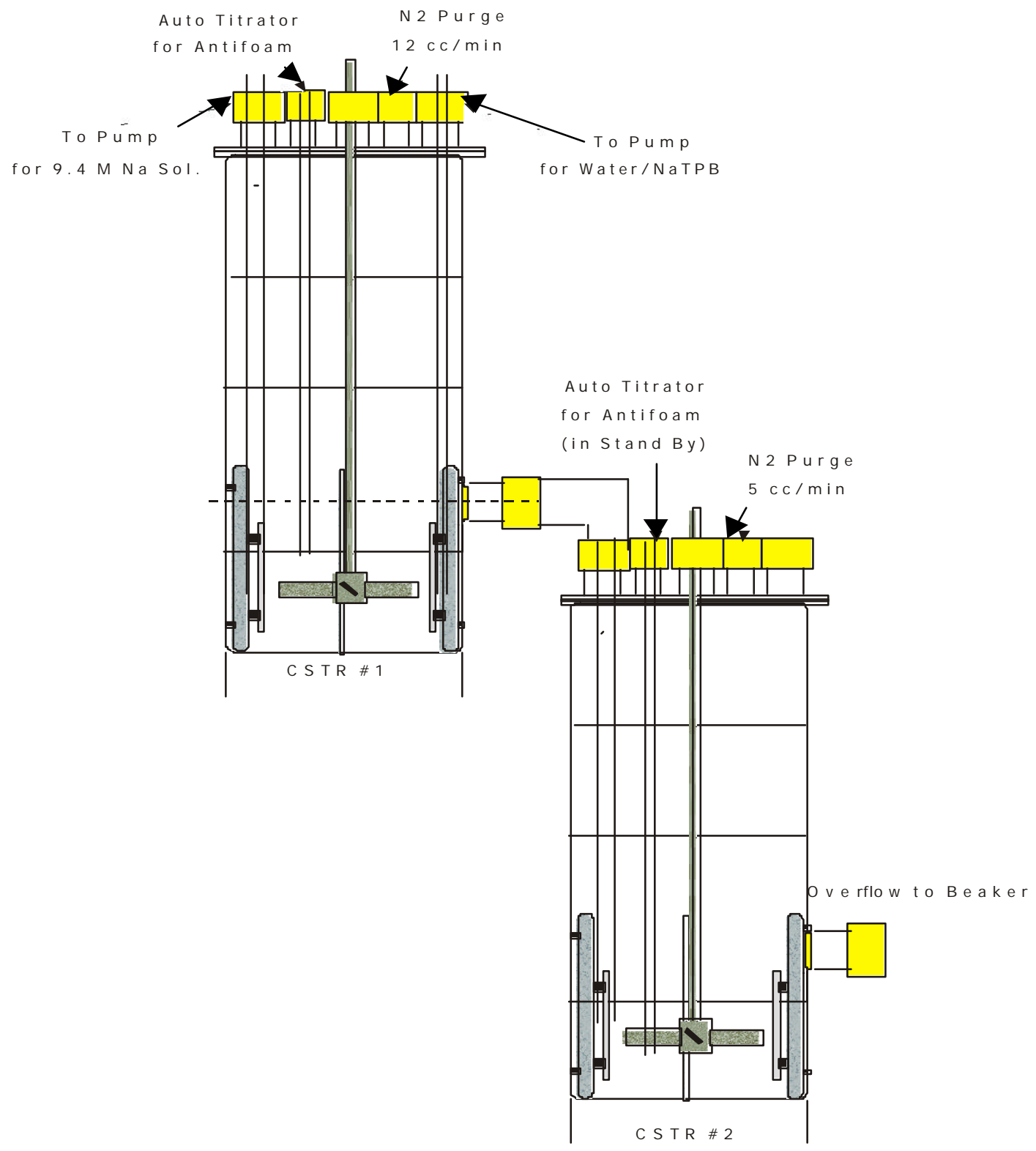

Figure 2 Schematic of Dual CSTR Precipitation System

Page 5 of 34 
Good mixing was achieved by using a 4-blade 2-inch diameter axial propeller at speeds up to 640 RPM and by four baffles at $90^{\circ}$ to each other within a cylindrical draft tube inside each CSTR (Figures 2 and 3). The vessel inside diameters were 5.0-inches, the baffles were 3" long by 0.5 " wide by $3 / 16$ " thick and were mounted $1 / 8$ " from the vessel wall. The cylindrical draft tube (simulating the cooling coils) was 3" ID by 3-1/4" OD and 2" long. The agitator speed of 640 RPM (tip speed of $11.2 \mathrm{ft} / \mathrm{sec}$ )was at the upper range of equivalent tip speeds as was used in the Peterson shielded cell tests. ${ }^{3}$ Two types of agitators were used; the first CSTR of each of the two identical rigs used a Servodyne Model 50003-30 agitator with a Model 50000-00 controller due to height constraints and the second CSTR of both rigs used a Lightnin Model L1U10F agitator.

The solutions were pumped into the reaction vessels using calibrated Masterflex Model 755090 pump controllers with Model 7518-10 pumpheads and either \# 14 or \#16 silicone or neoprene tubing. These tubing materials were chosen because they are chemically resistant to caustic solutions.

The nitrogen purge is designed to exclude oxygen from the vapor space, preventing a flammable mixture from accumulating in the vessels or offgas system. The nitrogen purge gas was set to $12.0 \mathrm{sccm}$, which was scaled from the actual plant purge rate. The nitrogen purge gas was introduced into the top of each vessel, well above the liquid or foam level, and was controlled by a MKS Instruments Model 647B Multi Gas Controller with MKS Instruments Type 1179, 0-500 sccm $\mathrm{N}_{2}$ mass flow controllers.

The IIT antifoam agents (B52 and PM) were prepared as 1:100 dilute solutions in DI water (based on densities of 1.0). ${ }^{6}$ These antifoam solutions were metered into the CSTR \#1, to maintain an antifoam level of $100 \mathrm{ppmV}$, with a TOA Electronics, LTD. Model ABT-511 automatic burette dispenser using a $20-\mathrm{mL}$ volume burette. The syringe dispenser could not dispense the very thick and viscous Surfynol DF-110D defoamer so this material was added approximately every hour in the neat form using calibrated micropipettes.

\subsubsection{Concentration and Washing Processes}

Figure 3 below is a drawing of the CSTR vessel with a port at the bottom for recirculation of the precipitate through a crossflow filter for concentration and washing. Figure 4 presents a drawing of the overall experimental setup for the concentration and washing steps.

During the concentration cycle, precipitate feed $(0.6 \mathrm{wt} \%)$ was added at $25 \mathrm{~mL} / \mathrm{min}$ and $1 / 100$ diluted antifoam was added at $0.25 \mathrm{~mL} / \mathrm{min}$ giving an antifoam concentration of $100 \mathrm{ppmV}$. Because of the high viscosity and the limited water solubility of Surfynol DF-110D, this antifoam could not be added to the vessel with the automatic burette, and had to be added periodically by calibrated pipette.

Precipitate feed was added using a Masterflex Model 7523-00 pump and Model 7020-50 pumphead and No. 16 silicone tubing to the vessel via a subsurface dip-tube, but wash water was added by dripping it down the vessel wall or along the agitator shaft. Wash water

Page 6 of 34 
addition along the agitator shaft caused it to be sprayed out over the surface of the precipitate as a fine spray. A wash water addition rate of 4 to $5 \mathrm{~mL} / \mathrm{min}$ was used with a $1 / 100$ diluted antifoam rate of $0.04 \mathrm{~mL} / \mathrm{min}$. Filter feed pump suction and discharges were located near the bottom of the vessel.

The crossflow filter was a Mott 0.5 micron stainless steel filter 6" long by "ID. The filter feed pump was a Cole-Parmer variable speed pump drive Model 75225-12 with a Model 101000-010 pumphead.

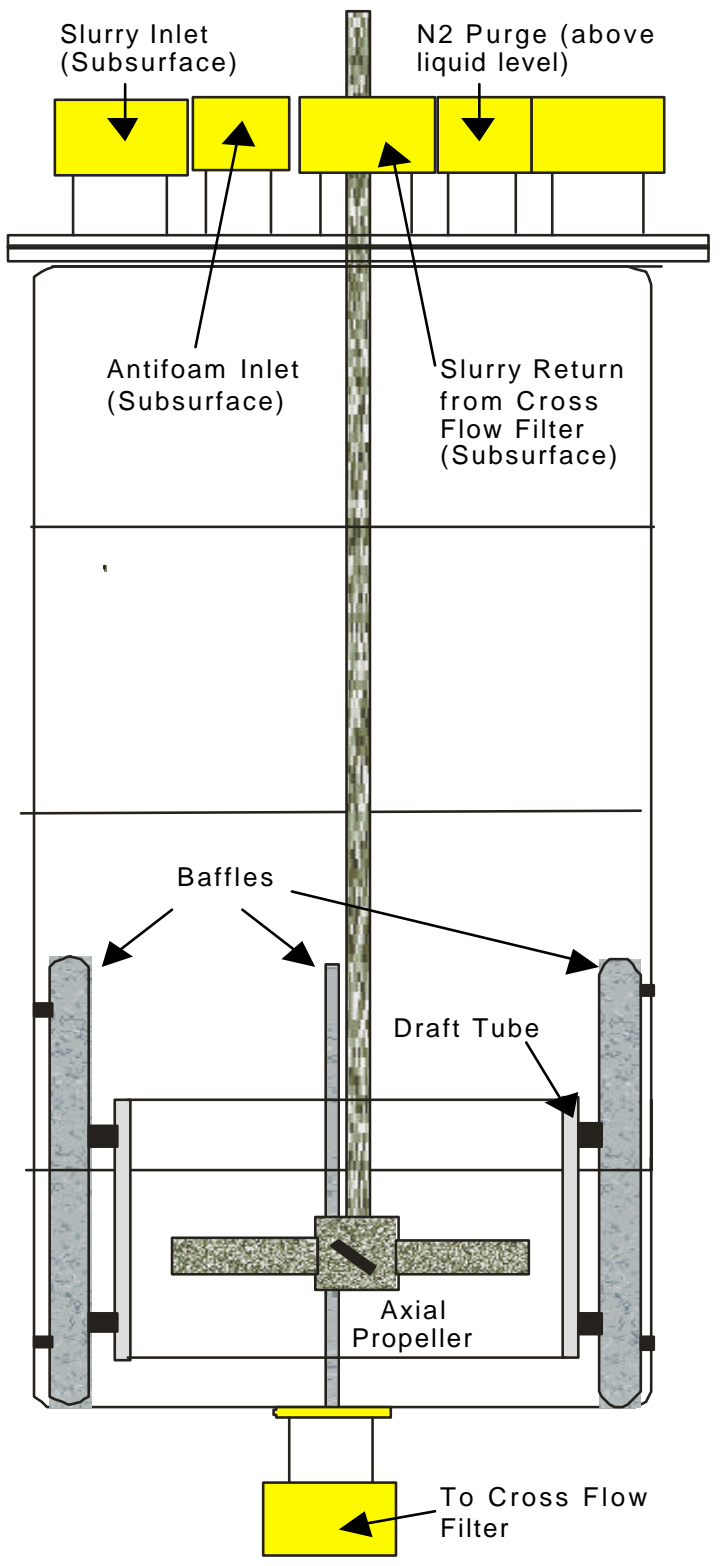

Figure 3 Sketch of the Concentration/Wash Vessel

Page 7 of 34 


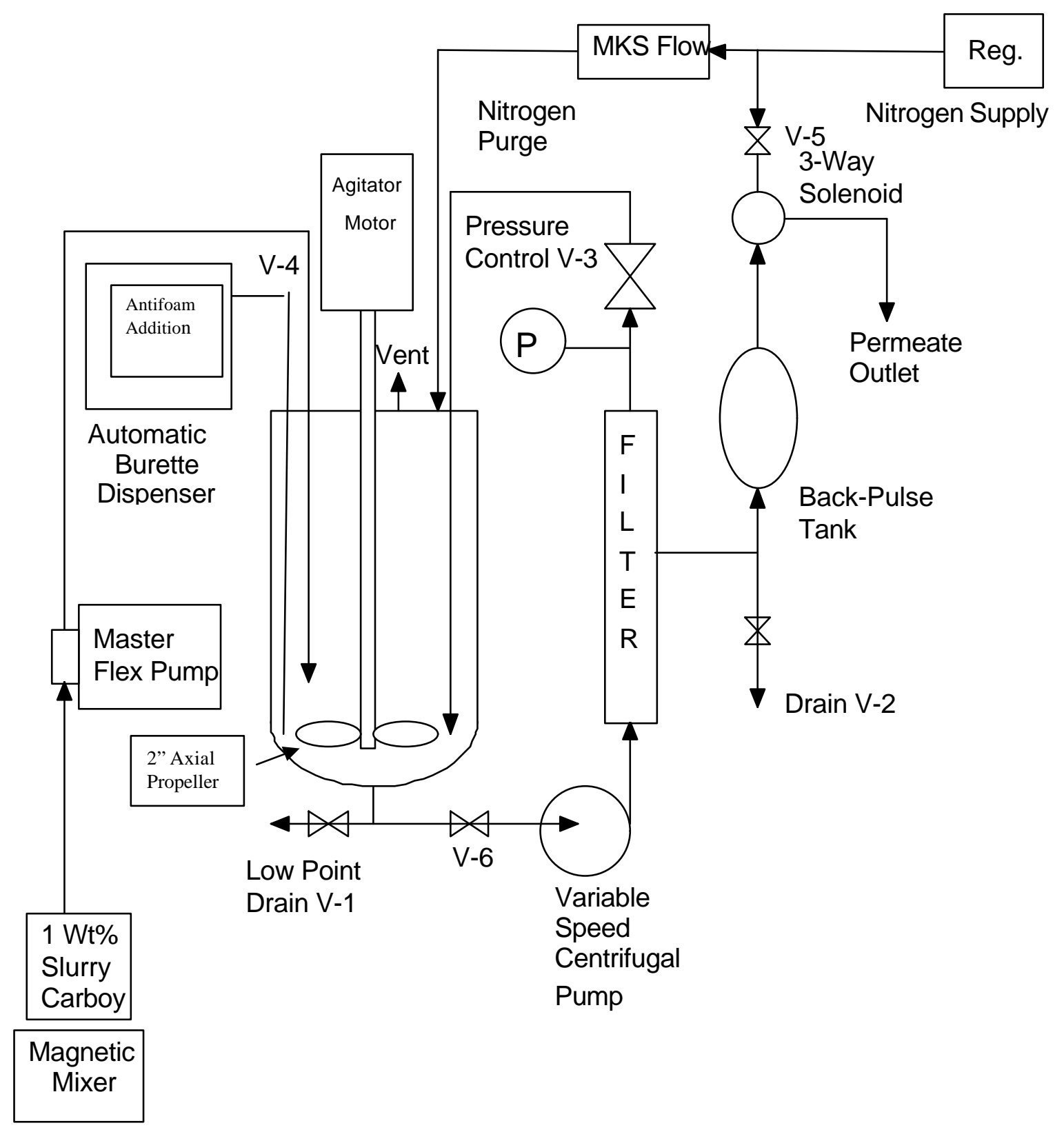

Figure 4 Schematic of Concentration and Washing Apparatus 


\subsection{DESCRIPTION OF EXPERIMENTS AND RESULTS}

\subsection{PRECIPITATION STEP}

\subsubsection{No Antifoam Baseline}

The first precipitation test was a baseline study with no antifoam or defoam agent added to the system.

We needed to make about $40-\mathrm{L}$ of each of the $0.6 \mathrm{wt} \%$ precipitate slurries to have a sufficient amount of slurry to perform the concentration and washing steps. This 40 liters of slurry was prepared in four 10-L batches. For each of the four 10-L batches we started with $5-\mathrm{L}$ of the 9.4 M Na salt solution from Table 1 and 5-L of DI water to which $380.585 \mathrm{~g}$ of the $0.55 \mathrm{M}$ NaTPB solution and $2.75 \mathrm{~g}$ of MST was added. These solutions were then well mixed.

CSTR \#1 was initially charged with about 1-L of premixed (in a carboy outside of the CSTR) precipitate slurry. This initial 1-L of slurry was prepared by slowly mixing equal volumes (500-mL each) of the $9.4 \mathrm{M}$ salt solution from the 5-L stock solution with $500-\mathrm{mL}$ of the DI water, NaTPB, MST stock solution. This slurry was then charged to CSTR \#1. The remaining salt solution and precipitant solutions were then immediately metered subsurface into CSTR \#1 at rates of $5.0 \mathrm{~mL} / \mathrm{min}$ and $5.4 \mathrm{~mL} / \mathrm{min}$ respectively.

Both CSTR 's were under a $12.0 \mathrm{sccm}$ nitrogen purge. The vessels were prepurged with nitrogen at $200 \mathrm{sccm}$ for about a hour before the precipitate was added.

At the end of an eight-hour shift the feed pumps agitators, and nitrogen purge were stopped until the next day.

Measurements were taken of the height of the slurry and any foam at about 20-30 minute intervals.

The feed pumps and purge were restarted at the same rate on subsequent shifts until $90 \%$ of the feed solutions had been added; at this point the remaining $10 \%$ of the feed solutions were added over about an 8 hour period at rates of $1.0 \mathrm{~mL} / \mathrm{min}$ and $1.1 \mathrm{~mL} / \mathrm{min}$ for the salt solution and NaTPB solution respectively. At this point the initial 10-L of precipitate slurry was produced.

At about the 1.5-L level in CSTR \#1 the precipitate would gravity overflow into CSTR \#2 and at about the 1.5-L level in CSTR \#2 the precipitate would gravity overflow into a collection carboy. The agitators were turned on once the propeller was well covered with slurry. After the initial 10-L of slurry was produced, the slurry was allowed to soak for 24 hours with agitation of 400 RPM. 
Little (less than $5 \%$ ) or no foam was observed in either CSTR \#1 or CSTR \#2 during this No Antifoam Baseline run. This indicated that the precipitation can be carried out without foaming if air (gas) is not injected into the slurry.

The remaining $30-\mathrm{L}$ of precipitate was produced in $10-\mathrm{L}$ increments as above but at a faster addition rate since this part of the test was just to produce enough precipitate for the subsequent concentration and washing cycles. During this production run the feed rates for the salt solution and NaTPB solution was increased to $13.0 \mathrm{~mL} / \mathrm{min}$ and $14.0 \mathrm{~mL} / \mathrm{min}$ respectively.

No foam generation was observed during the precipitation of this additional 30-L of slurry.

More details of the run can be found in the Run Plan document, SRT-PTD-2000-0021 Rev. 1, June 6, 2000 by P. R. Monson.

\subsubsection{IIT B52 Antifoam Test}

The first precipitation test with an antifoam agent was using $100 \mathrm{ppmV}$ of IIT B52 antifoam continuously added subsurface into CSTR \#1.

We again needed to make about $40-\mathrm{L}$ of the $0.6 \mathrm{wt} \%$ precipitate slurry to have a sufficient amount of slurry to perform the concentration and washing steps. This 40 liters of slurry was prepared in the same manner as in the No Antifoam Baseline case; in four 10-L batches except that $10.0 \mathrm{~mL}$ of the 1:100 dilution IIT B52 antifoam was added subsurface to the initial 1-L slurry over a 2 minute period using the automatic burette dispenser. This gave an initial level of $100 \mathrm{ppmV}$ of IIT B52 antifoam in the 1-L of slurry. This slurry was then charged to CSTR \#1. The remaining salt solution and precipitant solutions were then immediately metered subsurface into CSTR \#1 at rates of $5.0 \mathrm{~mL} / \mathrm{min}$ and $5.4 \mathrm{~mL} / \mathrm{min}$ respectively. The IIT B52 antifoam solution was also metered into CSTR \#1 subsurface a rate to maintain 100 ppmV of antifoam in CSTR \#1. The agitation speed was set at 640 RPM. No addition of antifoam was made to CSTR \#2. The remain part of the precipitation process was identical to that used in the No Antifoam case.

Little (less than $5 \%$ ) or no foam was observed in either CSTR \#1 or CSTR \#2 during this IIT B52 Antifoam run.

The remaining 30-L of precipitate was produced as in the No Antifoam case. The IIT B52 antifoam addition was likewise increased to maintain $100 \mathrm{ppmV}$ of antifoam in CSTR \#1.

No foam generation was observed during the precipitation of this additional 30-L of slurry. 
WSRC-TR-2000-00261, REVISION 0

\subsubsection{IIT PM Antifoam Test}

The second precipitation test with an antifoam agent was using $100 \mathrm{ppmV}$ of IIT PM antifoam continuously added subsurface into CSTR \#1. This test was identical to the IIT B52 test except IIT PM was the antifoam agent.

Little (less than $5 \%$ ) or no foam was observed in either CSTR \#1 or CSTR \#2 during this IIT PM Antifoam run.

The remaining 30-L of precipitate was produced as in the IIT B52 case. The IIT PM antifoam addition was likewise increased to maintain $100 \mathrm{ppmV}$ of antifoam in CSTR \#1.

No foam generation was observed during the precipitation of this additional 30-L of slurry.

\subsubsection{Surfynol DF-110D Defoamer Test}

The third precipitation test with an antifoam agent was using $100 \mathrm{ppmV}$ of Surfynol DF-110D antifoam continuously added subsurface into CSTR \#1.

We inadvertently used Surfynol DF-110D instead of Surfynol DF-110L in all of the tests reported here. Air Products, the supplier of Surfynol defoamers, says that the active components of both Surfynol DF-110D and Surfynol DF-110L are identical, the only difference being that 110L has an additional solvent of ethylene glycol not present in 110D. Surfynol DF-110D has about $32 \%$ active ingredient and Surfynol DF-110L has $20 \%$ of the same active ingredient. Dr. Alex Nikolov of IIT advised that we should see little or no difference in defoaming performance between Surfynol DF-110D and Surfynol DF-110L.

We again needed to make about $40-\mathrm{L}$ of the $0.6 \mathrm{wt} \%$ precipitate slurry to have a sufficient amount of slurry to perform the concentration and washing steps. This 40 liters of slurry was prepared in the same manner as in the No Antifoam Baseline case, in four 10-L batches. The initial 1-L of slurry was prepared as in the other antifoam runs except for the method of antifoam addition. Due to the insolubility of Surfynol DF-110D in water, $0.1 \mathrm{~mL}$ of the undiluted Surfynol DF-110D antifoam was added subsurface to this initial 1-L slurry with a calibrated pipette. This gave an initial level of $100 \mathrm{ppmV}$ of Surfynol DF-110D antifoam in the 1-L of slurry. During the precipitation of the initial 10-L of slurry, the Surfynol DF-110D antifoam was added $0.15 \mathrm{~mL}$ every 40 minutes into CSTR \#1 subsurface to maintain 100 ppmV of antifoam in CSTR \#1. No addition of antifoam was made to CSTR \#2.

Little (less than $5 \%$ ) or no foam was observed in either CSTR \#1 or CSTR \#2 during this Surfynol DF-110D Antifoam run.

The remaining 30-L of precipitate was produced in as in previous runs. The Surfynol DF$110 \mathrm{D}$ antifoam addition was likewise increased to maintain $100 \mathrm{ppmV}$ of antifoam in CSTR $\# 1$.

Page 11 of 34 
WSRC-TR-2000-00261, REVISION 0

No foam generation was observed during the precipitation of this additional 30-L of slurry.

\subsection{CONCENTRATION STEP}

Concentration cycles were performed with, IIT B52, IIT PM, and Surfynol DF-110D antifoam, respectively. Two concentration cycles with no antifoam addition were completed.

No foaming was observed in any of the concentration and washing cycles when air was not introduced below the liquid surface. The only exception was that the slurry containing IIT PM was foamed due to high agitation (high agitation was used because of poor mixing). High agitation rates, sub-surface air introduction, or a combination of both can lead to severe foaming and should be eliminated in any plant design.

The addition of $300 \mathrm{ppm}$ of IIT B52 antifoam demonstrated the ability to de-foam a batch of $10 \mathrm{wt} \%$ KTPB slurry containing no antifoam, which had been intentionally foamed by high agitation and subsurface air introduction. In a similar experiment in which high agitation rates caused the foaming during the washing cycle of the IIT PM run, the addition of more IIT PM had little effect on the foam. The addition of 1,000 ppm of IIT B52 to this batch also had little effect on the foam. Addition of IIT PM first may have hindered the effectiveness of the B52 antifoam.

Nitrite washing efficiency was found to be greater than that predicted by a well mixed tank washing operation. One possible explanation is that the upper portion of the slurry was not well mixed even at agitator speeds of 1,400-1,800 RPM. Wash water introduced to this surface would then flow through in plug flow displacing the supernate instead of diluting it and a high overall washing efficiencies would result.

\subsubsection{No Antifoam Baseline}

\subsubsection{Run 1}

The first no antifoam concentration run was the first experimental run to be performed in the test unit. Initial filter flux rates were well above the planned $25 \mathrm{~mL} / \mathrm{min}$ due to the specified trans-membrane pressure of 5 Psig. Attempts to reduce the filter flux by restricting the slurry flow while maintaining the trans-membrane pressure resulted in completely plugging the filter tube. The plug was cleared by removing the flow restriction (completely open valve V-3) and back pulsing the contents of the back pulse tank into the unit. The back pulse tank was then refilled with permeate already collected and the process was repeated until the plug cleared. At that point it was decided to abandon the operational requirement of a constant transmembrane pressure of 5 Psig and allow it to vary as needed to maintain the permeate flow of $25 \mathrm{~mL} / \mathrm{min}$. 
WSRC-TR-2000-00261, REVISION 0

The initial slurry pump speed of about $30 \%$ of full scale was capable of producing permeate at the specified $25 \mathrm{~mL} / \mathrm{min}$ flow rate. However, as the solids content of the slurry increased the pump speed was increased to maintain this flow and the level in the concentration vessel.

\section{No foaming was observed during the entire concentration cycle}

The weight percent insoluble solids of the product slurry was measured to be $9.42 \%$ (target of 10 wt \%).

With no foaming observed in this run, which had the greatest potential for foaming, it was decided to demonstrate the foaming character of the KTPB slurry by introducing subsurface air at $25 \mathrm{~mL} / \mathrm{min}$ with a high agitation rate (1,400 RPM's). This operation appeared to increase the level in the concentration vessel by several hundred milliliters in less than an hour. Foam (25\%) also formed on the surface of the slurry, which was un-mixed even at the high agitation rate. Slurry pumping efficiency was also dramatically reduced by the presence of the foam. Centrifugal pumps are known not to pump foam well.

The addition of $300 \mathrm{ppm}$ of IIT B52 antifoam demonstrated the ability to de-foam the batch of KTPB slurry. The level in the vessel dropped to the point prior to the addition of air and the pumping efficiency of the centrifugal slurry pump was regained. The vessel was then deinventoried and cleaned for the next concentration cycle. This slurry was not washed. A second run was performed to produce slurry for washing.

\subsubsection{Run 2}

The purpose of this run was to produce concentrated slurry for demonstrating the washing cycle. The 0.6 wt\% KTPB slurry was not produced in the CSTR's, but was made by adding NaTPB solution to salt solution in a 52 liter carboy. The carboy was well mixed and allowed to stand for more than a week. The KTPB solids floated to the top allowing about half of the permeate to be decanted from the bottom reducing the time to concentrate the slurry. This slurry was fed to the filter unit and was concentrated. No attempt was made to control feed rates or permeate flow. This procedure produced some foam in the resulting slurry. Therefore, the concentrated slurry also had a significant amount of foam.

The foam was broken by sealing the vessel and repeatedly pulling a vacuum (6 in $\mathrm{Hg}$ absolute) followed by rapid venting. This procedure causes the small air bubbles in the foam to combine forming larger bubbles that rise to the surface and break. Initially the slurry volume would expand by about 1.5 liters, indicating significant amounts of air in the slurry. After repeated cycles the slurry would expand by only $200-300 \mathrm{~mL}$, indicating that the air contained in the slurry was between $40-50 \mathrm{~mL}$ at atmospheric pressure. Washing of the slurry was then performed. This approach could not be used in larger vessels because of the large forces generated on a larger vessel. 
WSRC-TR-2000-00261, REVISION 0

\subsubsection{IIT B52 Antifoam Test}

Concentration of a CSTR slurry prepared with IIT B52 antifoam did not produce any foaming and appeared to be more fluid than the tests without antifoam addition.

During the concentration cycle, precipitate feed $(0.6 \mathrm{wt} \%)$ was added at $25 \mathrm{~mL} / \mathrm{min}$ and $1 / 100$ diluted antifoam was added at $0.25 \mathrm{~mL} / \mathrm{min}$ giving an antifoam concentration of $100 \mathrm{ppmV}$. As in all the concentration runs performed, the speed of the slurry pump was increased as the solids content of the vessel increased to maintain permeate flow at $25 \mathrm{~mL} / \mathrm{min}$. The weight percent insoluble solids of the product slurry were measured to be $9.94 \%$. The vessel was then de-inventoried and cleaned for the next concentration cycle.

\subsubsection{IIT PM Antifoam Test}

Concentration of a CSTR slurry prepared with IIT PM60 antifoam did not produce any foaming and appeared to be more fluid than the tests without antifoam addition.

During the concentration cycle, precipitate feed $(0.6 \mathrm{wt} \%)$ was added at $25 \mathrm{~mL} / \mathrm{min}$ and $1 / 100$ diluted antifoam was added at $0.25 \mathrm{~mL} / \mathrm{min}$ giving an antifoam concentration of $100 \mathrm{ppmV}$. As in all the concentration runs performed, the speed of the slurry pump was increased as the solids content of the vessel increased to maintain permeate flow at $25 \mathrm{~mL} / \mathrm{min}$. The slurry pump failed in the later stages of the cycle and had to be replaced. A small amount of slurry $(\sim 150 \mathrm{~mL})$ was lost while changing out the pump and the cycle was completed.

The weight percent insoluble solids of the product slurry were measured to be $10.80 \%$. The vessel was not de-inventoried. Washing of the KTPB slurry was performed after nitrite analysis was determined.

\subsubsection{Surfynol DF-110D Test}

Because of the high viscosity and the limited water solubility of Surfynol DF-110D, this antifoam could not be added to the vessel with the automatic burette, and was added periodically by calibrated pipette $(0.2 \mathrm{~mL}$ every 50 minutes).

Concentration of a CSTR slurry prepared with Surfynol DF-110D antifoam did not produce any foaming and appeared to be more fluid than the tests without antifoam addition.

During the concentration cycle, precipitate feed $(0.6 \mathrm{wt} \%)$ was added at $25 \mathrm{~mL} / \mathrm{min}$ and 0.20 $\mathrm{ml}$ of undiluted antifoam was added every 50 minutes giving an antifoam concentration of $100 \mathrm{ppmV}$.

The weight percent insoluble solids of the product slurry were measured to be $10.14 \%$. The vessel was not de-inventoried. Washing of the KTPB slurry was performed after nitrite analysis was determined.

Page 14 of 34 


\subsection{PRECIPITATE WASHING CYCLE}

Wash water requirements were calculated using a well mixed model assuming constant wash water and permeate flow rates. Total slurry volume was used instead of the volume of salt solution contained in the $10 \mathrm{wt} \%$ slurry. The volume of the back pulse tank $(150 \mathrm{~mL})$ was subtracted from the indicated slurry volume since this permeate was not part of the slurry makeup. Starting nitrite concentrations were measured by ADS. The desired washed slurry nitrite target was $0.01 \mathrm{M}(460 \mu \mathrm{g} / \mathrm{mL})$. This calculation is presented below:

$[$ Wash Water $(\mathrm{mL})]=[\text { Slurry Volume }(\mathrm{mL})]^{*} \operatorname{Ln}[$ Initial Nitrite $\left.(\mu \mathrm{g} / \mathrm{mL}) / 460 \mu \mathrm{g} / \mathrm{mL})\right]$

Samples of permeate were taken periodically during the washing cycle and analyzed for nitrite and soluble NaTPB. Wash water was added at 4 to $5 \mathrm{~mL} / \mathrm{min}$ along the wall of the vessel or along the spinning agitator shaft. Wash water addition along the agitator shaft caused it to be sprayed out over the surface of the precipitate as a fine spray. A 1/100 diluted antifoam rate of $0.04 \mathrm{~mL} / \mathrm{min}$ was used in the B52 and IIT PM antifoam runs. Filter feed pump suction and discharges were located near the bottom of the vessel. Agitator speed was set to maintain a well mixed state (900 - 1,300 RPM). An agitation speed of 1700 RPM lead to foaming in the IIT PM run.

\subsubsection{No Antifoam Baseline}

Precipitate left in the vessel after concentration (Run 2) was washed. The initial nitrite concentration for this run was not determined. Since the salt solution makeup was consistent with the other runs, the nitrite concentration and the required amount of wash water would also be similar. Wash water volume was set at 7 liters as was used in previous runs. Figure 5 presents the nitrite profile during the washing operation. Final nitrite concentration was 495 $\mu \mathrm{g} / \mathrm{mL}$ (target 410 to $510 \mu \mathrm{g} / \mathrm{mL}$ ).

Figure 6 presents the NaTPB concentration versus the volume of permeate generated. A total of 58.46 grams of NaTPB were washed out of the slurry which represents $60 \%$ of the excess NaTPB assuming no NaTPB removed during concentration cycle. Since no samples of precipitate slurry were removed during concentration, the mass of excess NaTPB present was calculated based upon the mass of NaTPB used for the precipitation (259.5 gms).

Total Excess NaTPB $=(259.5 \mathrm{gm})(0.375)=97.31 \mathrm{gm}$

Ratio of NaTPB to Total TPB solids for $60 \%$ excess NaTPB $=(0.6 / 1.6)=0.375^{*}$

* Assuming no NaTPB removed during concentration cycle. 
WSRC-TR-2000-00261, REVISION 0

Nitrite from No Antifoam Washing

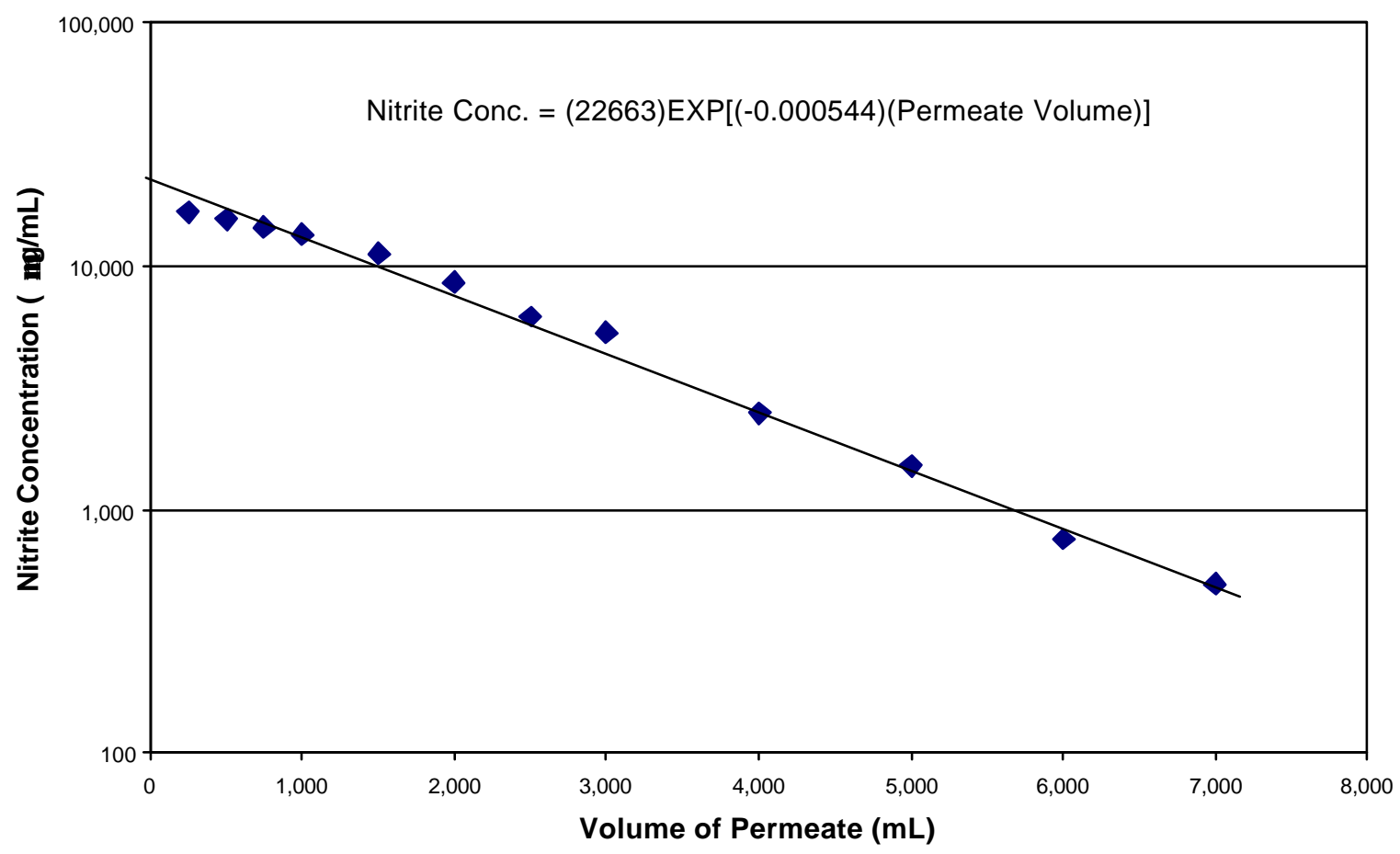

Figure 5 Nitrite Profile for the No Antifoam Washing Cycle

Page 16 of 34 
NaTPB from No Antifoam Washing

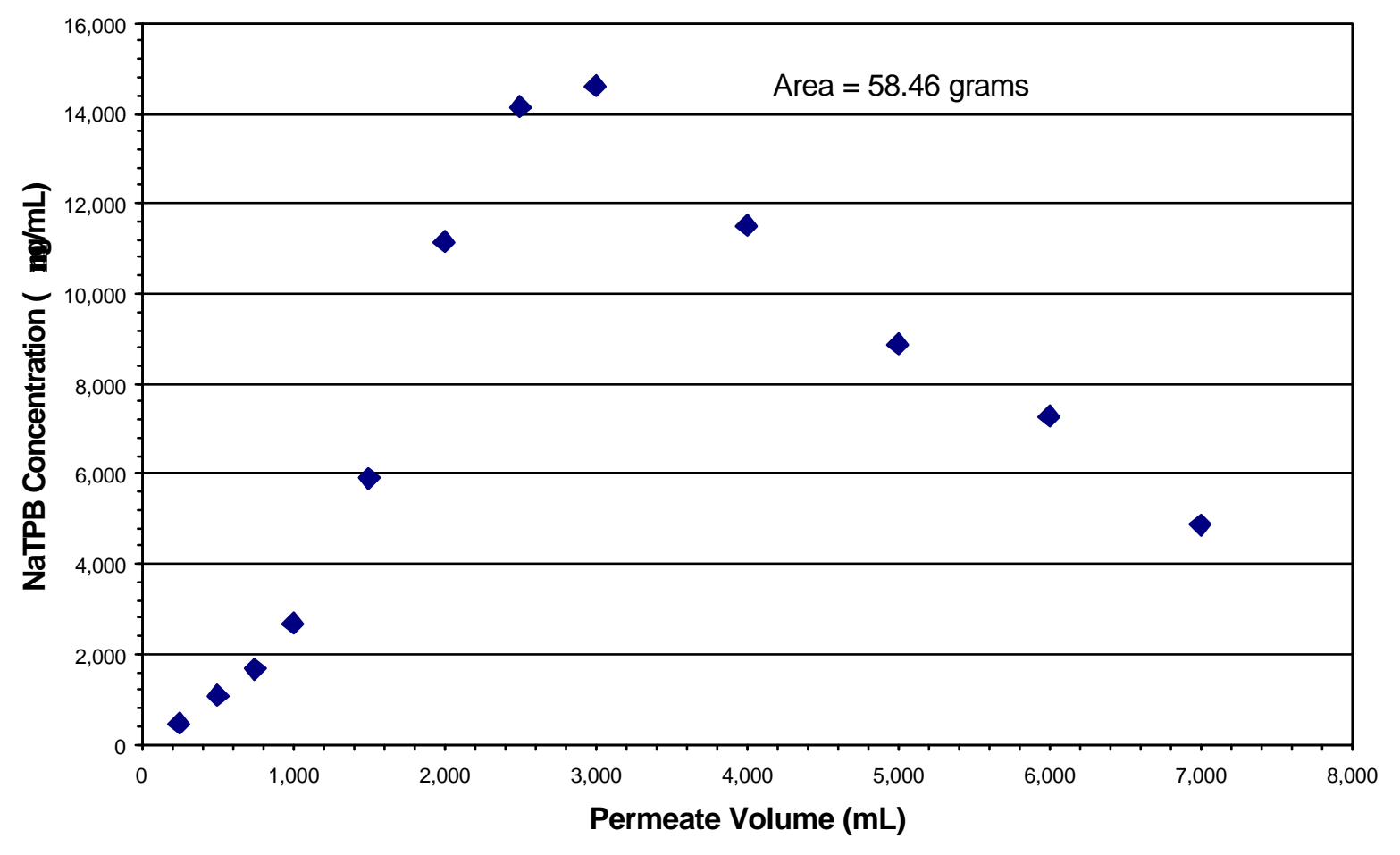

Figure 6 NaTPB Profile for No Antifoam Washing Cycle

\subsubsection{IIT B52 Antifoam Test}

Previously concentrated slurry $(1,882 \mathrm{gm} / 1,678 \mathrm{~mL} @ 1.121 \mathrm{SpG})$ was pumped to the filtration vessel. Concentration permeate $(160 \mathrm{~mL})$ from the concentration cycle was used to flush the carboy and inventory the back pulse tank. A slurry volume used in the wash water calculation was $1,838 \mathrm{~mL}$. The initial nitrite concentration for this run was $16,338 \mu \mathrm{g} / \mathrm{mL}$. The calculation presented above yields a wash water requirement of $6,562 \mathrm{~mL}$ to obtain 460 $\mu \mathrm{g} / \mathrm{mL}$ final concentration. Total permeate removed was set at 7,000 $\mathrm{mL}$ to re-concentrate and account for the TPB ion washed out of the slurry. The Figures 7 and 8 below present the nitrite and NaTPB profiles for this wash cycle.

The measured final nitrite concentration of $80 \mu \mathrm{g} / \mathrm{mL}$ was well below the target nitrite level of $460 \mu \mathrm{g} / \mathrm{mL}$. Nominal agitation (800-1,000 RPM's) in a narrow tall vessel leads to an upper volume of slurry which is not well mixed. The addition of wash water to the surface of the precipitate flows through this upper portion of slurry in plug flow improving overall washing efficiency. While the data indicates that the slurry was not well mixed, movement at the surface was observed. 
A total of 8.90 grams of NaTPB was washed out with the permeate or $12.68 \%$ of the calculated mass of NaTPB present. The mass of NaTPB present was calculated as follows:

Total Excess NaTPB $=(1,882 \mathrm{gm})(0.0994)(0.375)=70.15 \mathrm{gm}$

Ratio of NaTPB to Total TPB solids for $60 \%$ excess NaTPB $=(0.6 / 1.6)=0.375^{*}$

* Assuming no NaTPB removed during concentration cycle.

\section{Nitrite from IIT B52 Washing}

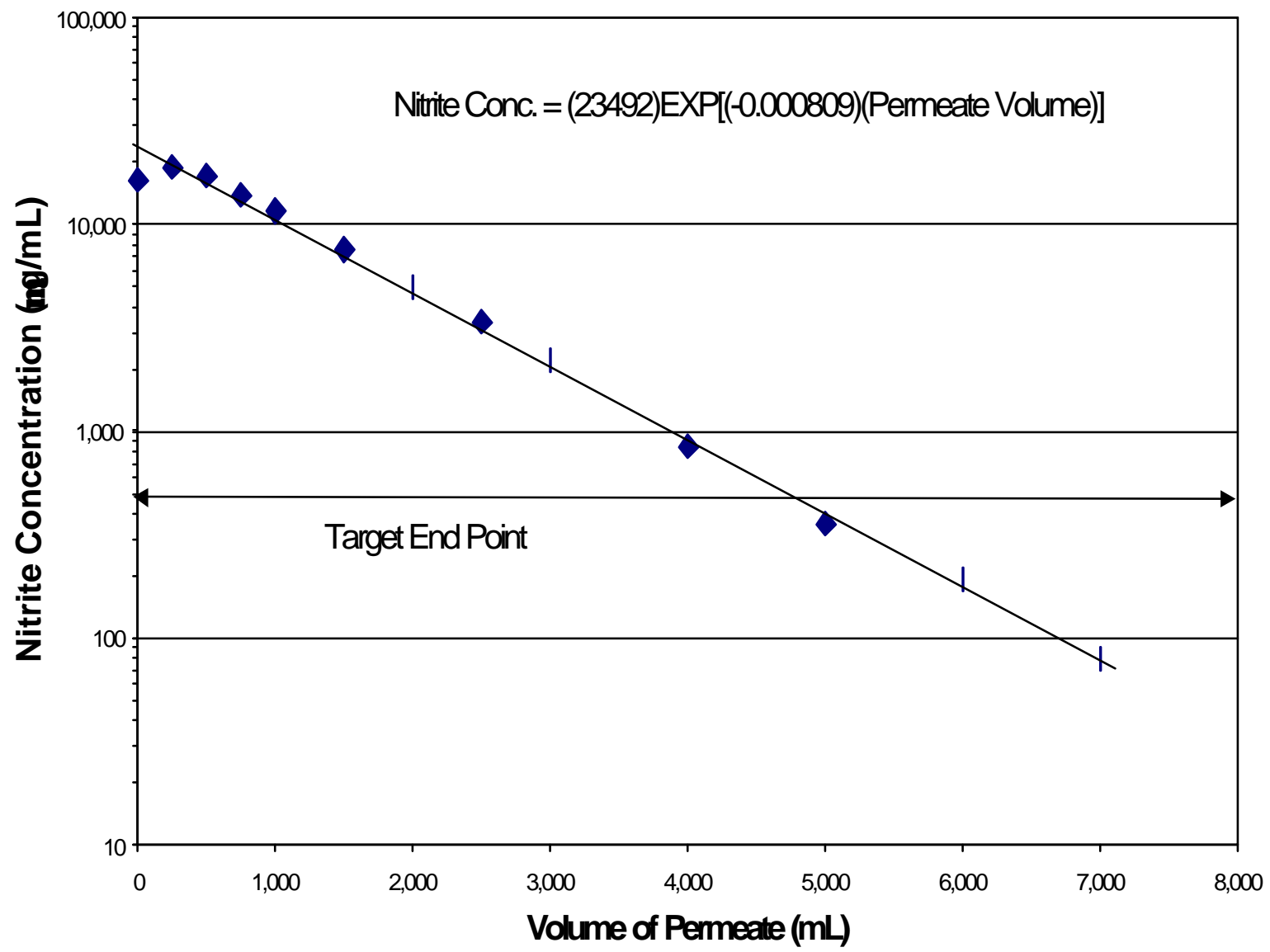

Figure 7 Nitrite Profile for the IIT B52 Antifoam Washing Cycle

Page 18 of 34 
NaTPB from IIT B52 Washing

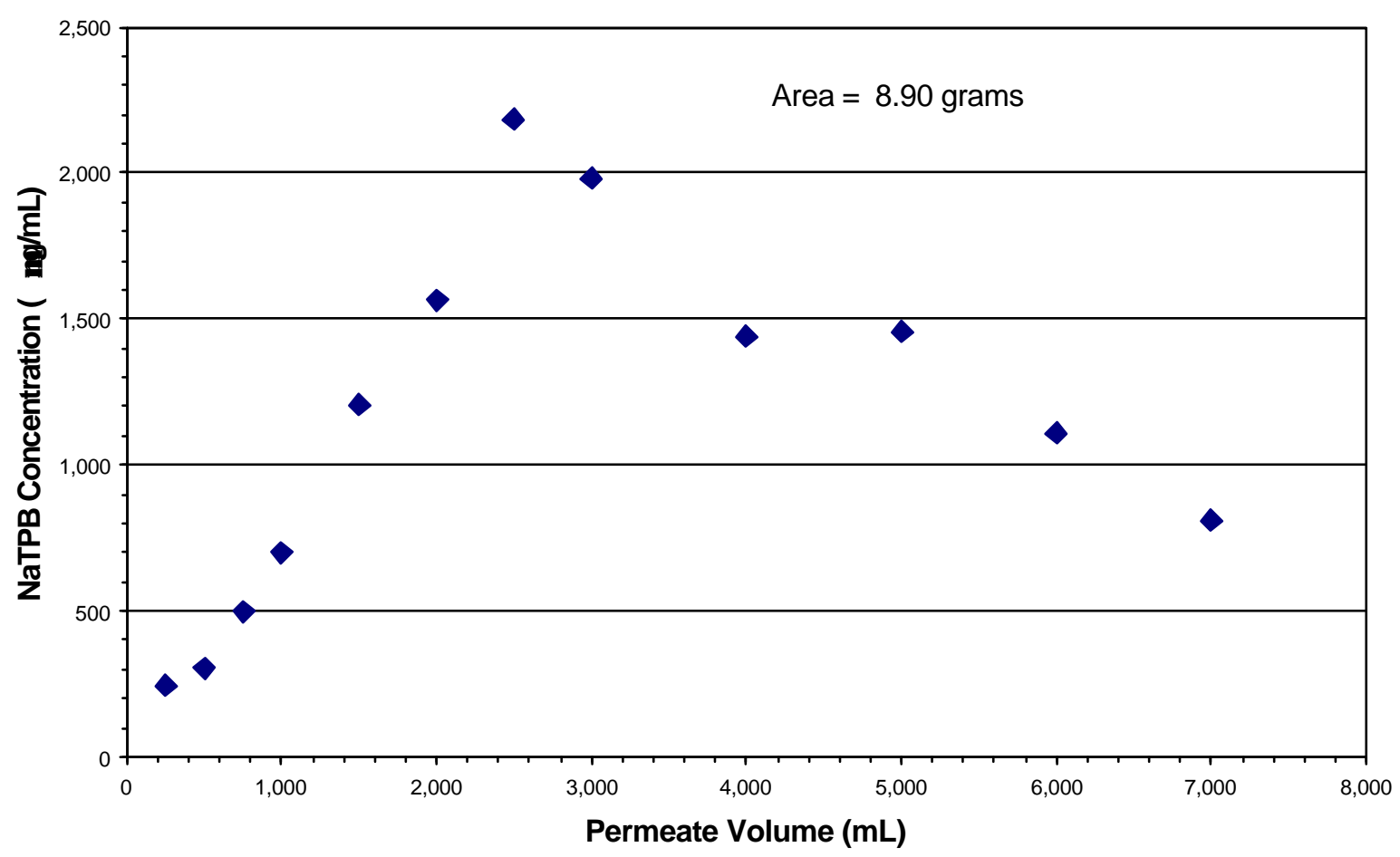

Figure 8 NaTPB Profile for the IIT B52 Antifoam Washing Cycle

\subsubsection{IIT PM Antifoam Test}

Precipitate left in the vessel after concentration was washed. The total vessel inventory was $1,905 \mathrm{~mL}$. A slurry volume used in the wash water calculation was $1,750 \mathrm{~mL}$. The initial nitrite concentration for this run was $22,700 \mu \mathrm{g} / \mathrm{mL}$. The calculation presented above yields a wash water requirement of $6,823 \mathrm{~mL}$ to obtain $460 \mu \mathrm{g} / \mathrm{mL}$ final concentration. The volume of permeate collected matched the volume of wash water introduced. Agitation rate was increased to 1,700 RPM's after 5,000 mL of permeate had been collected. 
This degree of agitation resulted in foaming of the precipitate slurry. A sample of the slurry had a measured specific gravity of $0.77 \mathrm{gm} / \mathrm{mL}$. Indicating that the slurry contained significant amounts of gas.

The Figure 9 below presents the nitrite profile for this wash cycle. The final nitrite concentration, $(100 \mu \mathrm{g} / \mathrm{mL})$, is well below that predicted from a well mixed model. It must be concluded that the vessel was not well mixed and wash water flowed through a portion of the slurry in plug flow (likely the foam layer on top). Following washing, filtration was continued with the filter permeate being returned to the top of the vessel. Analysis of permeate collected after an hour of reflux resulted in a nitrite concentration of $261 \mu \mathrm{g} / \mathrm{mL}$. This increased nitrite concentration indicates that portions of the slurry (foam) were completely stagnant and contained high concentrations of nitrite.

Figure 10 presents the NaTPB profile for this washing cycle.

A total of 18.88 grams of NaTPB was washed out with permeate or $23.76 \%$ of the excess.

Total Excess NaTPB $=(1,750 \mathrm{~mL})(1.121 \mathrm{gm} / \mathrm{mL})(0.1080)(0.375)=79.45 \mathrm{gm}$

Ratio of NaTPB to Total TPB solids for $60 \%$ excess NaTPB $=(0.6 / 1.6)=0.375^{*}$

* Assuming no NaTPB removed during concentration cycle. 
WSRC-TR-2000-00261, REVISION 0

Nitrite from IT PM Washing

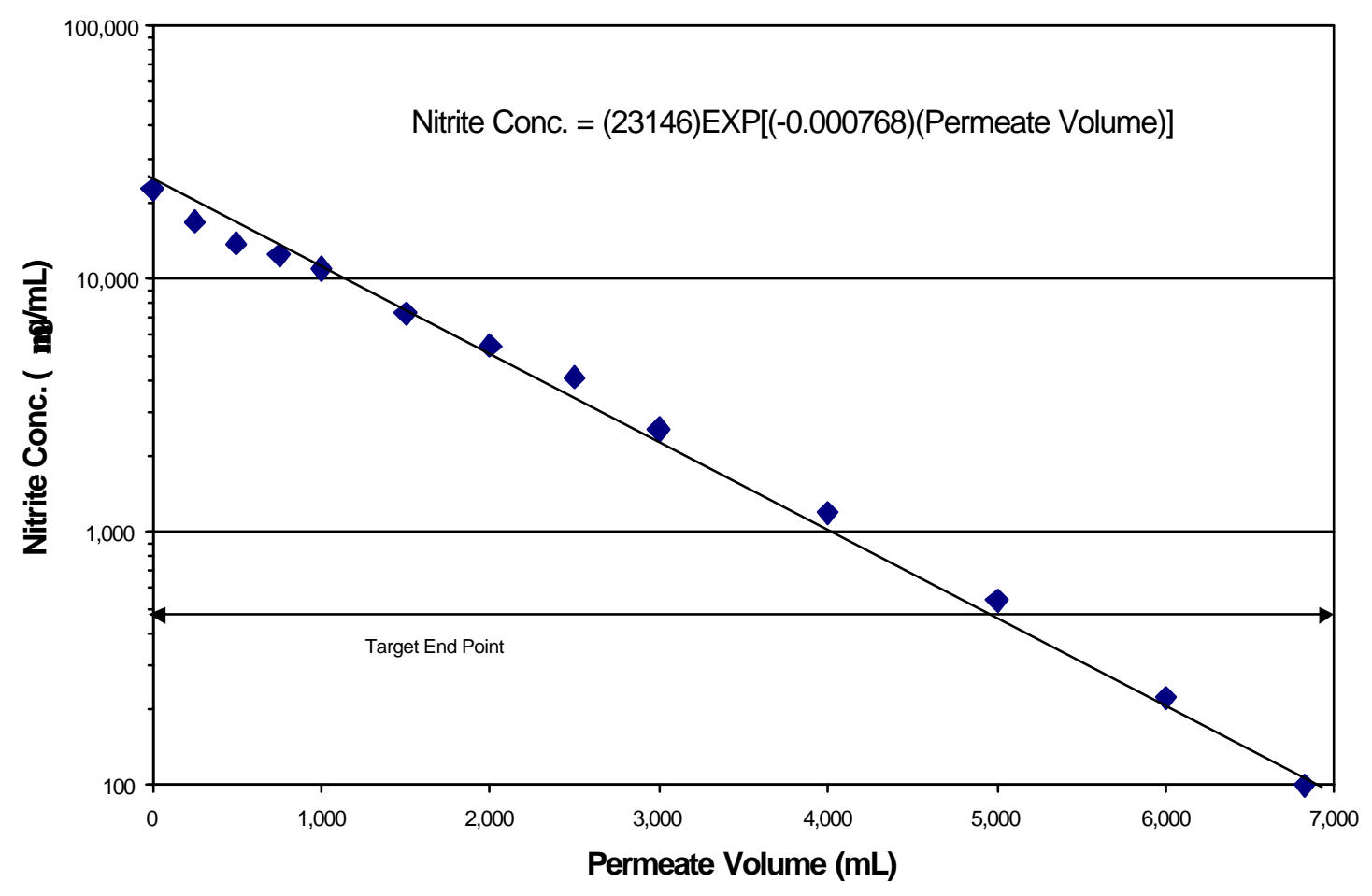

Figure 9 Nitrite Profile During IIT PM Antifoam Washing

Page 21 of 34 


\section{NaTPB from IIT PM Washing}

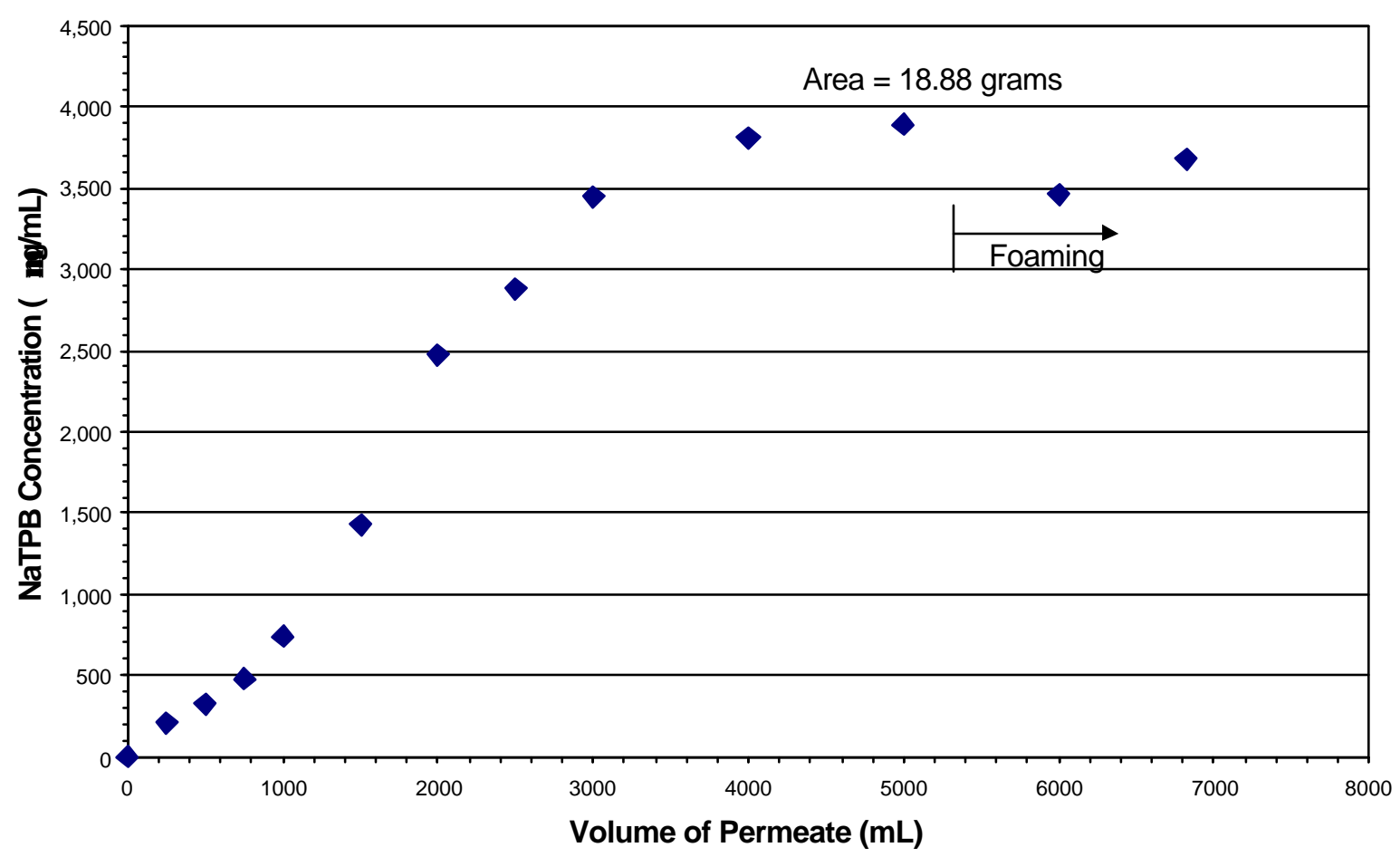

Figure 10 NaTPB Profile for the IIT PM Antifoam Washing Cycle

\subsubsection{Surfynol DF-110D Test}

Precipitate left in the vessel after concentration was washed. The total vessel inventory was $1,954 \mathrm{~mL}$. A slurry volume used in the wash water calculation was $1,804 \mathrm{~mL}$. The initial nitrite concentration for this run was $19,554 \mu \mathrm{g} / \mathrm{mL}$. The calculation presented above yields a wash water requirement of $6,765 \mathrm{~mL}$ to obtain $460 \mu \mathrm{g} / \mathrm{mL}$ final concentration. Total permeate removed was set at 7,000 $\mathrm{mL}$ to re-concentrate and account for the NaTPB washed out of the slurry. Figures 11 and 12 present the nitrite and NaTPB profiles, respectively for this washing cycle.

The final permeate sample had a nitrite concentration of $308 \mu \mathrm{g} / \mathrm{mL}$. (Target $460 \mu \mathrm{g} / \mathrm{mL}$ )

A total of 15.52 grams of NaTPB was washed out with permeate or $20.18 \%$ of the excess NaTPB.

Total NaTPB $=(1,804 \mathrm{~mL})(1.121 \mathrm{gm} / \mathrm{mL})(0.1014)(0.375)=76.90 \mathrm{gm}$

Ratio of NaTPB to Total TPB solids for $60 \%$ excess NaTPB $=(0.6 / 1.6)=0.375^{*}$ 
* Assuming no NaTPB removed during concentration cycle.

Nitrite from Surrynol DF-110D Washing

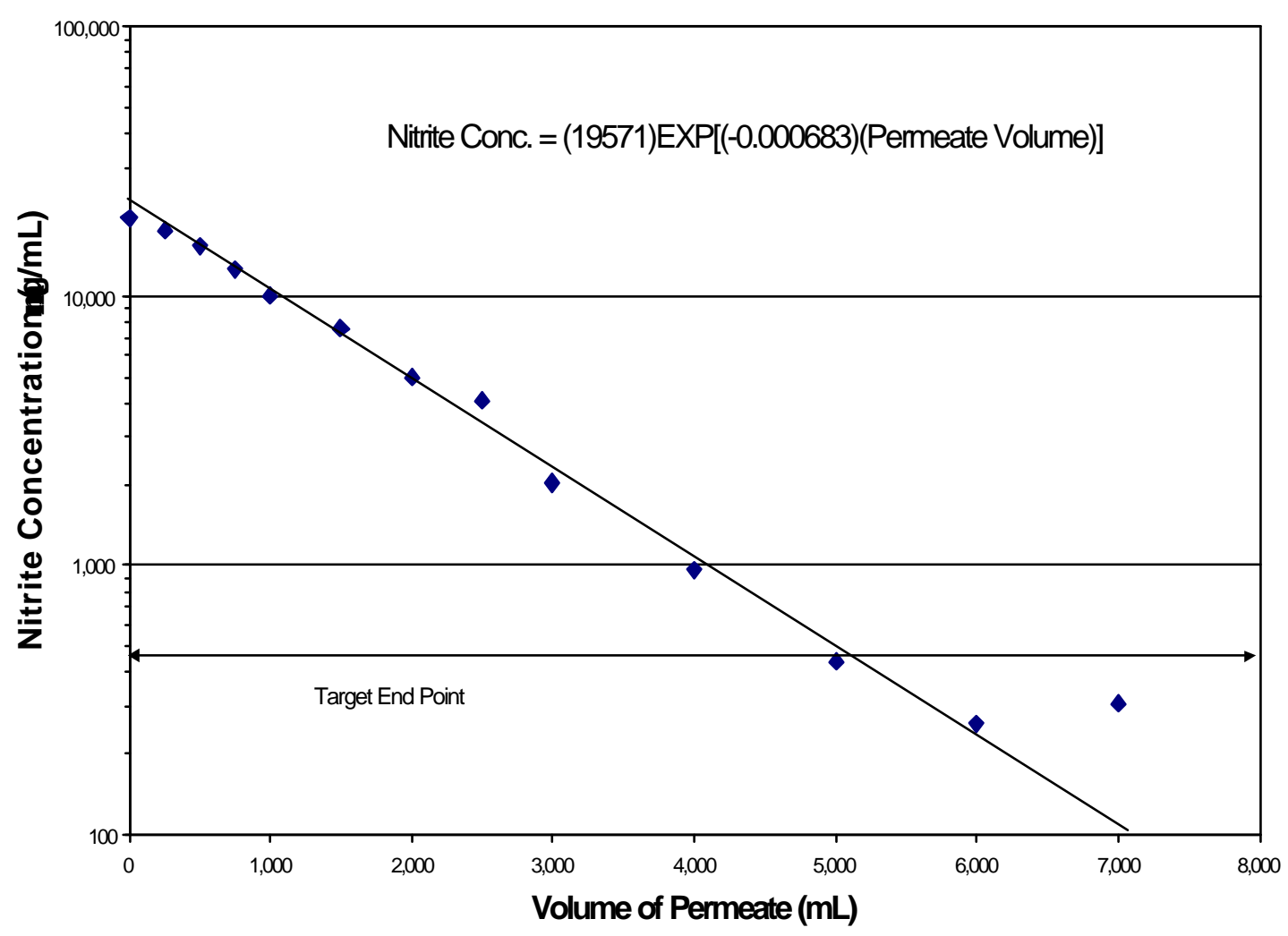

Figure 11 Nitrite Profile for the Surfynol DF 110D Antifoam Washing Cycle 
NaTPB from Surfynol DF-110D Washing

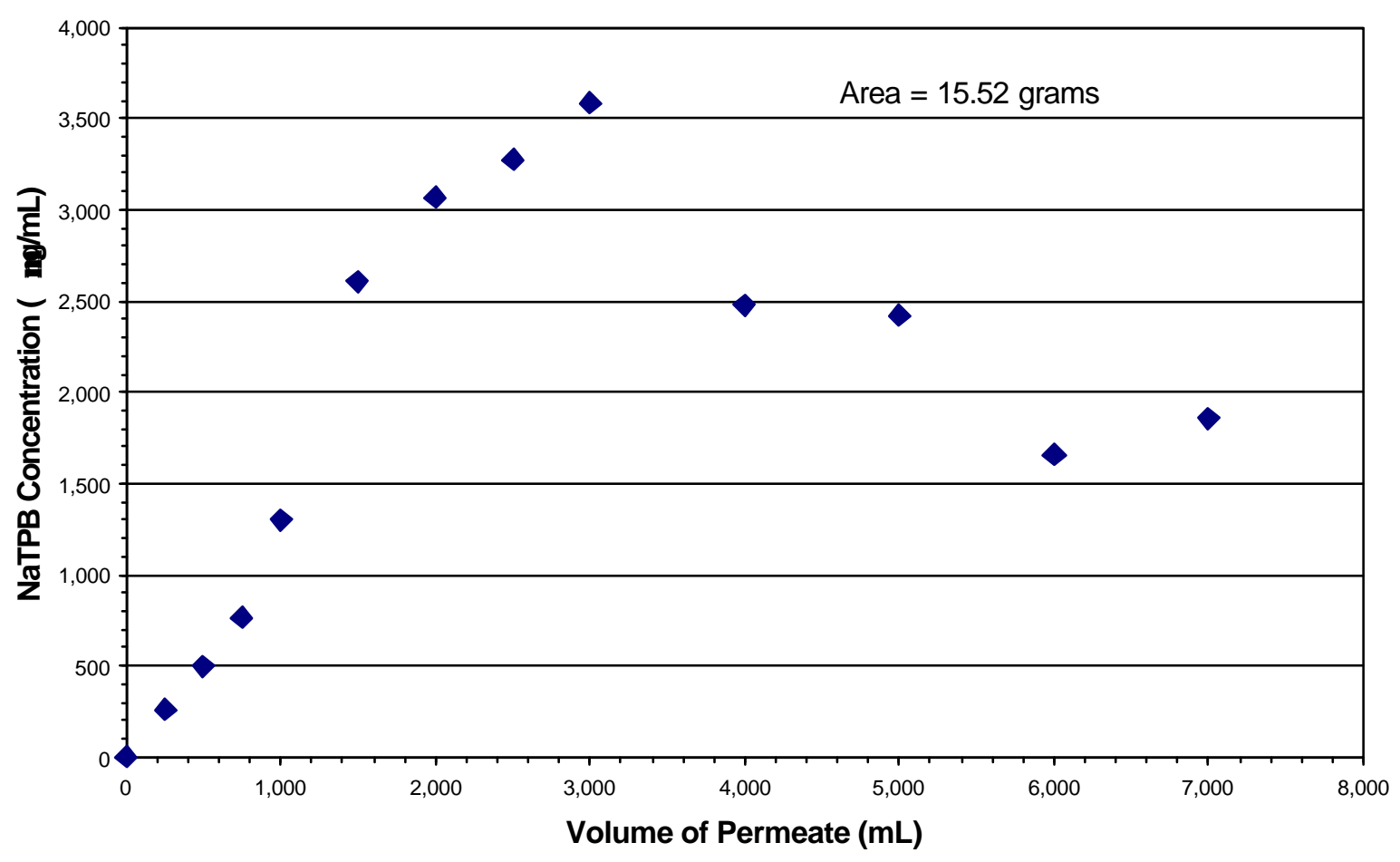

Figure 12 NaTPB Profile for the Surfynol DF 110D Antifoam Washing Cycle

\subsection{Rheological Properties Of Product Slurries}

The rheological character of the product slurries are presented in Figure 13 below. The presence of antifoam agent strongly affected the rheology. The yield stress, based upon a Bingham model, was reduced by about a factor of five when the slurry contained antifoam agent. Due to the air entrainment in these slurries the rheograms should only be used for comparing slurries and not for design purposes. All flow curves are for increasing shear rate and were taken at $25^{\circ} \mathrm{C}$. 


\section{Rheological Flow Curves}

(all are $10 \mathrm{wt} \%$ Slurry)

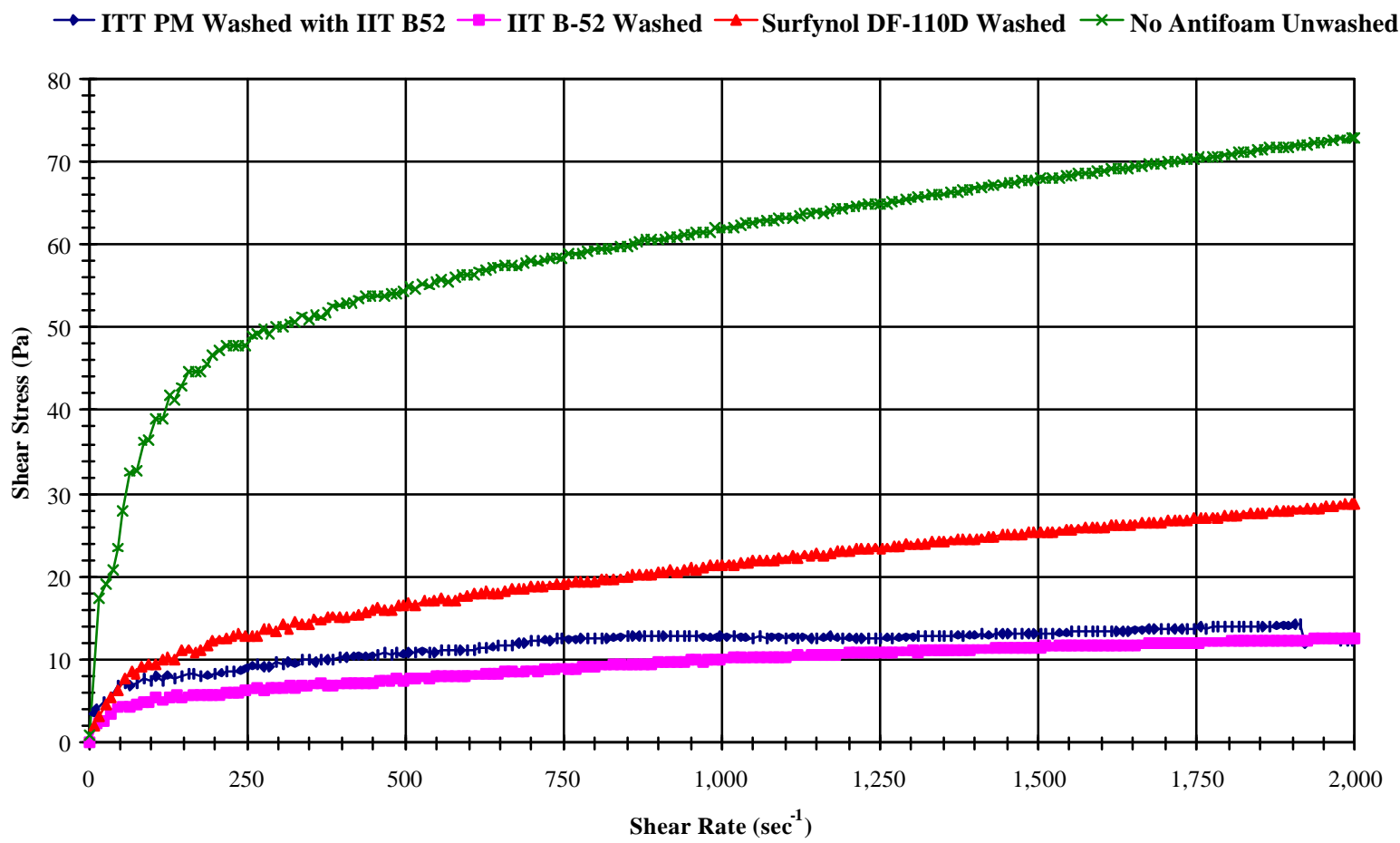

Figure 13. Rheological Increasing Shear Rate Flow Curves for Product Slurries

\subsection{FOAM COLUMN TESTS}

Two glass foam columns were fabricated by the SRTC Glass Shop to be used in a series of tests to investigate the effectiveness of the candidate antifoam/defoam agents.

These tests were necessary since little or no foam was generated during normal STTPB operations. Similar foam column tests were used by IIT to test their antifoams.

The columns were about 24" long by 1" ID and 24" long by 2.5 " ID both graduated in mm on two sides. The bottom was fitted with a 10-16 micron sintered glass disk, which held the slurry in the column but allowed a nitrogen purge to bubble up through the slurry and out the top of the column. A stopcock was provided below the fritted disk to allow deinventory of the column and cleaning of the fritted disk. A schematic of the foam column is shown in Figure 5.

Videotape of the experiments provided a near continuous record of the foam column results. 
The starting material for all tests was the No Antifoam concentrated (unwashed) $10 \mathrm{wt} \%$ insoluble solids KTPB slurry produced in the Precipitation and Concentration steps of this simulated STTPB Antifoam study. Between tests the columns were cleaned by rinsing several times with DI water, acetone and methanol to remove any residual antifoam on the column walls or within the fritted disk.

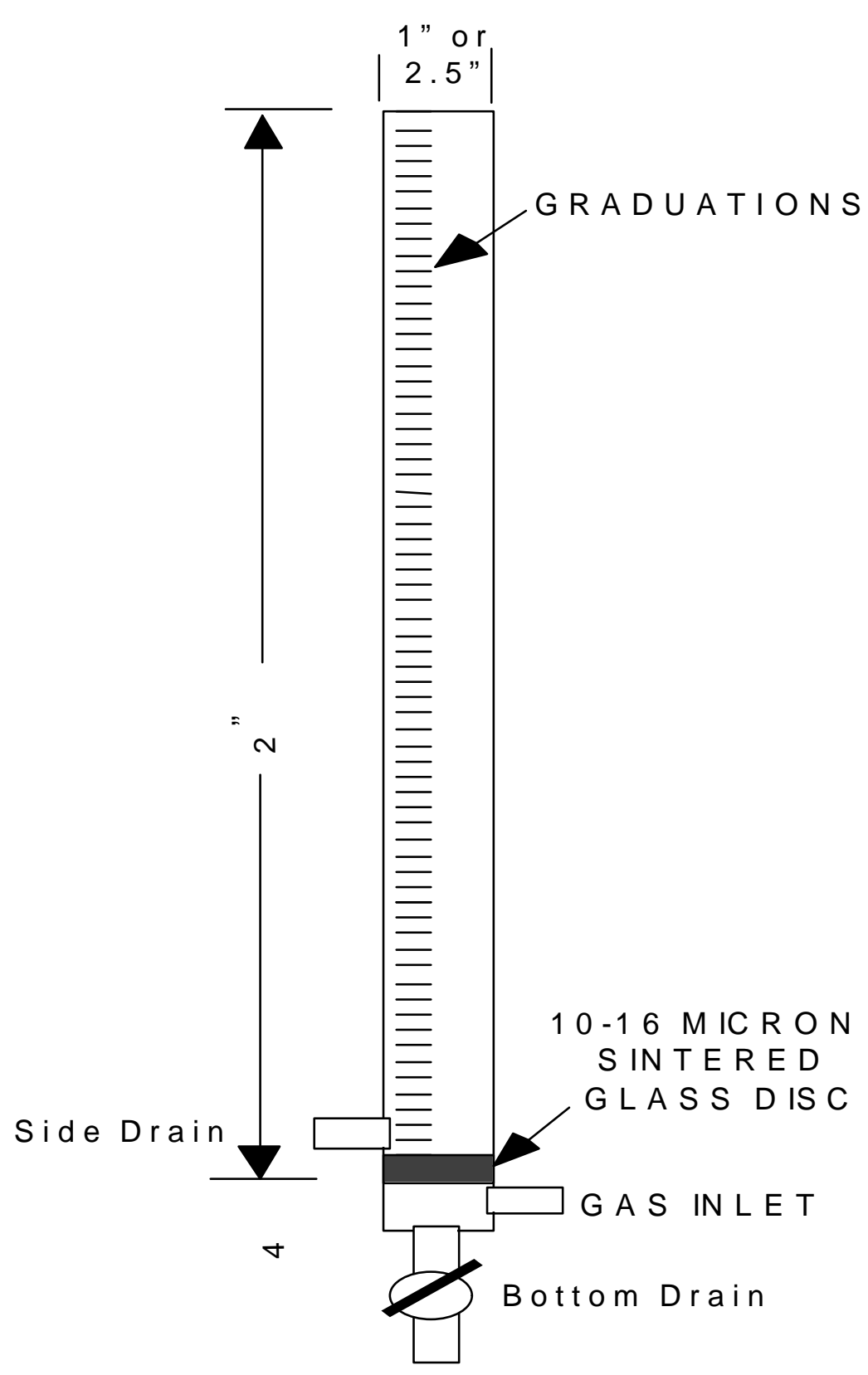

Figure 14 Schematic of the Foam Column Apparatus 


\subsubsection{Testing Protocol and Results}

Initial testing was carried out in the 1" diameter (small) column and the results with B52 antifoam were inconclusive (i.e., it was much less effective than was observed by IIT). This B52 antifoam was then shipped back to IIT and IIT confirmed that its effectiveness was very low, $<10 \%$ of what it originally tested at IIT. IIT then sent us a new shipment of more effective B52 antifoam which was used in all of our 2-1/2" diameter (large) column tests.

The testing protocol was essentially identical for all three antifoam/defoam agents tested with the exception that IIT B52 and IIT PM were added as 5:1 dilutions in DI water and the Surfynol DF-110D was added undiluted due to its insolubility in water.

The large (2-1/2") foam column was initially charged with $200 \mathrm{~mL}$ of the unwashed $10 \%$ insoluble solids No Antifoam KTPB slurry. A nitrogen purge of $500 \mathrm{sccm}$ was passed through the fritted disk and slurry for about 35 minutes until the foam level stabilized. 1000 ppm of active antifoam/defoam agent was added to the column and the new foam level noted. The results are shown in Table 2. In a second series of tests, $100 \mathrm{ppm}$ of active antifoam/defoam agent was premixed with the slurry and then carefully pumped into the column. The nitrogen purge of $500 \mathrm{sccm}$ was passed through the fritted disk for about 35 minutes and the foam levels recorded and summarized in Table 2 Test \#2. The final test was identical to test \#2 except $1000 \mathrm{ppm}$ of antifoam/defoam agent was used. As can be seen in Table 2 and Figure 15, IIT B52 was the most effective defoamer (Test \#1) and the most effective antifoamer (Tests \# 2 and \#3). at about $350 \%$ foam. After adding 1,000 ppmV of IIT B52 antifoam the foam dropped to about $20 \%$ foam. 
Table 2 Result of Large Foam Column Tests.

\begin{tabular}{|c|c|c|c|}
\hline & IIT B52 & IIT PM & $\begin{array}{l}\text { Surfynol DF-110D } \\
\end{array}$ \\
\hline Test \#1 & $\begin{array}{l}\text { Foam rose from } 6 \mathrm{~cm} \text { to } \\
31 \mathrm{~cm} \text { in } 35 \text { min. Added } \\
1000 \text { ppmV antifoam, } \\
\text { foam dropped to } 6.5 \mathrm{~cm} \text {. } \\
\text { Most Effective } \\
\text { Defoamer for Test \#1 }\end{array}$ & $\begin{array}{l}\text { Foam rose from } 6 \mathrm{~cm} \text { to } \\
31 \mathrm{~cm} \text { in } 35 \mathrm{~min} \text {. Added } \\
1000 \mathrm{ppmV} \text { antifoam, } \\
\text { foam dropped to } 23.5 \mathrm{~cm} \text {. }\end{array}$ & $\begin{array}{l}\text { Foam rose from } 6 \mathrm{~cm} \text { to } \\
29 \mathrm{~cm} \text { in } 35 \text { min. Added } \\
1000 \mathrm{ppmV} \text { antifoam, } \\
\text { foam dropped to } 10 \mathrm{~cm} .\end{array}$ \\
\hline Test \#2 & $\begin{array}{l}\text { Pre-mixed } 100 \mathrm{ppmV} \text { of } \\
\text { antifoam and Slurry. } \\
\text { Foam rose from } 5.9 \mathrm{~cm} \text { to } \\
7.6 \mathrm{~cm} \text { in } 20 \text { min. } \\
\text { Most Effective } \\
\text { Antifoamer for Test } \# 2\end{array}$ & $\begin{array}{l}\text { Pre-mixed } 100 \mathrm{ppmV} \text { of } \\
\text { antifoam and Slurry. } \\
\text { Foam rose from } 6.1 \mathrm{~cm} \text { to } \\
20 \mathrm{~cm} \text { in } 20 \mathrm{~min} .\end{array}$ & $\begin{array}{l}\text { Pre-mixed } 100 \mathrm{ppmV} \text { of } \\
\text { antifoam and Slurry. } \\
\text { Foam rose from } 6.1 \mathrm{~cm} \text { to } \\
13 \mathrm{~cm} \text { in } 20 \mathrm{~min} .\end{array}$ \\
\hline Test \#3 & $\begin{array}{l}\text { Pre-mixed } 1000 \mathrm{ppmV} \text { of } \\
\text { antifoam and Slurry. } \\
\text { Foam remained constant } \\
\text { at } 6.1 \mathrm{~cm} \text { for } 20 \mathrm{~min} \text {. } \\
\text { Most Effective } \\
\text { Antifoamer for Test \#3 }\end{array}$ & $\begin{array}{l}\text { Pre-mixed } 1000 \mathrm{ppmV} \text { of } \\
\text { antifoam and Slurry. } \\
\text { Foam rose from } 6 \mathrm{~cm} \text { to } \\
12.1 \mathrm{~cm} \text { in } 20 \mathrm{~min} .\end{array}$ & $\begin{array}{l}\text { Pre-mixed } 1000 \mathrm{ppmV} \text { of } \\
\text { antifoam and Slurry. } \\
\text { Foam rose from } 6 \mathrm{~cm} \text { to } \\
9.5 \mathrm{~cm} \text { in } 20 \text { min. }\end{array}$ \\
\hline
\end{tabular}

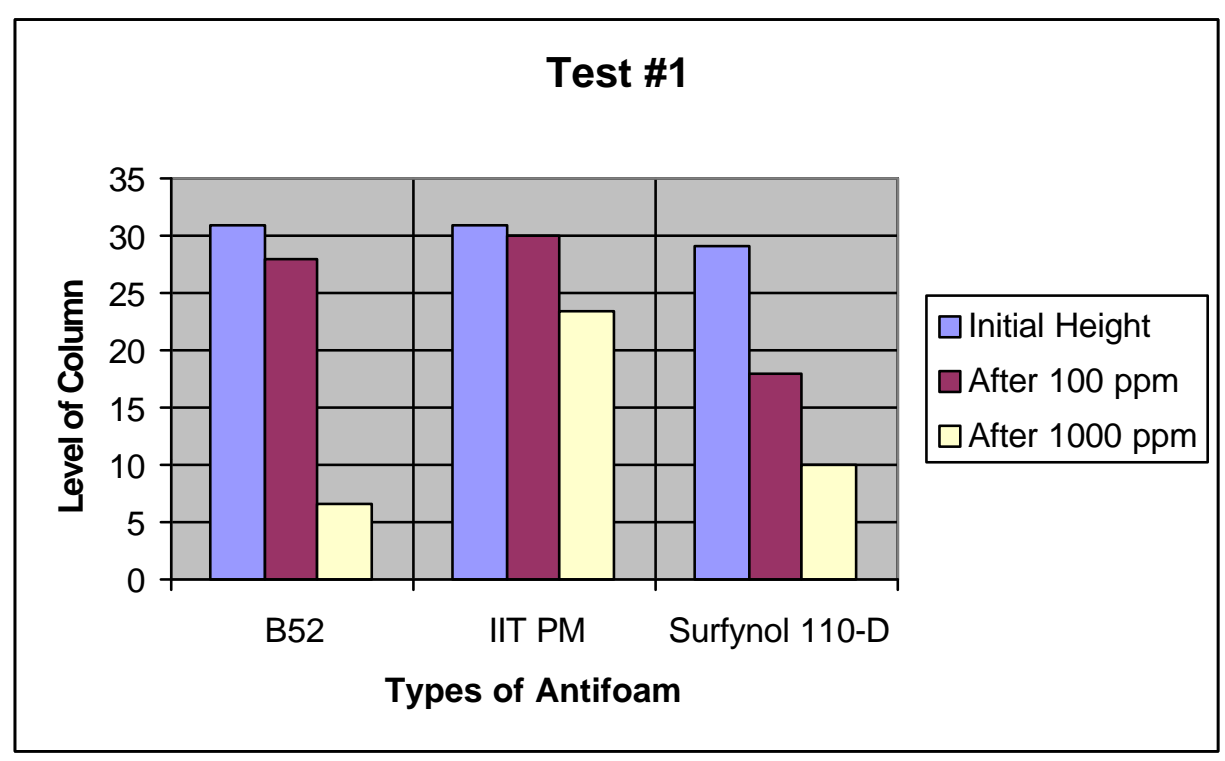

Figure 15 Large Foam Column Test \#1 


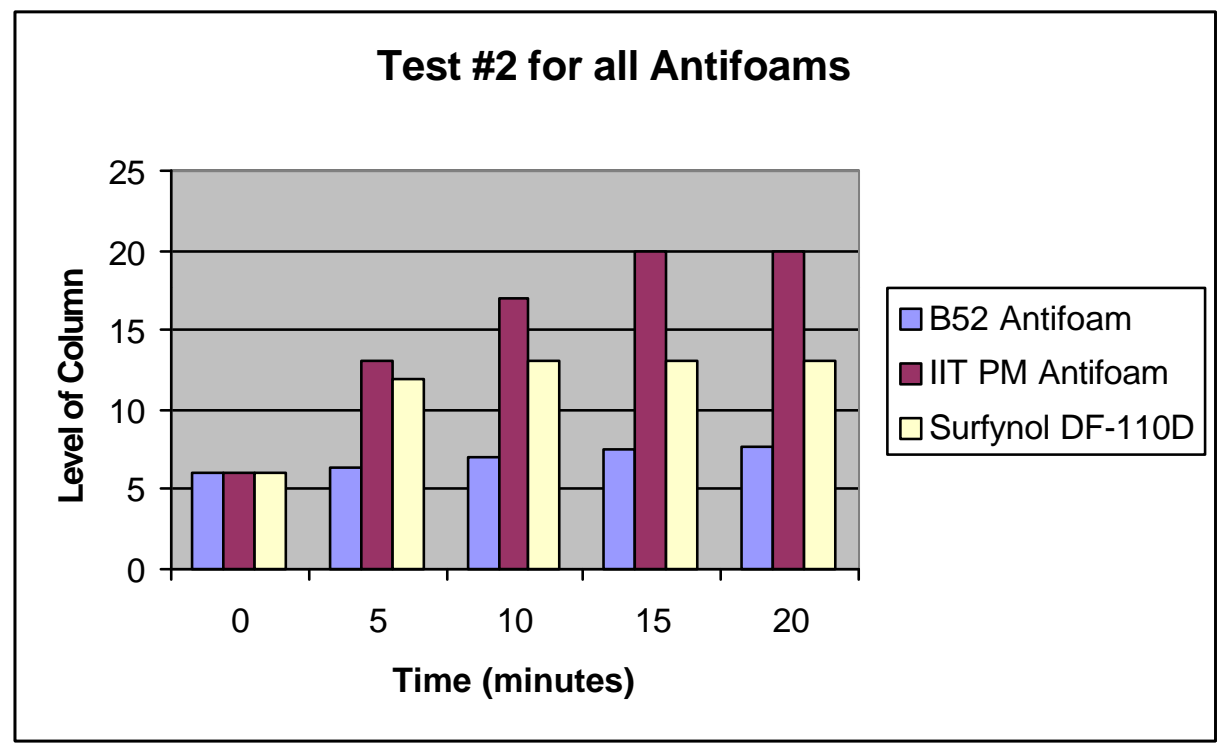

Figure 16 Large Foam Column Test \# 2

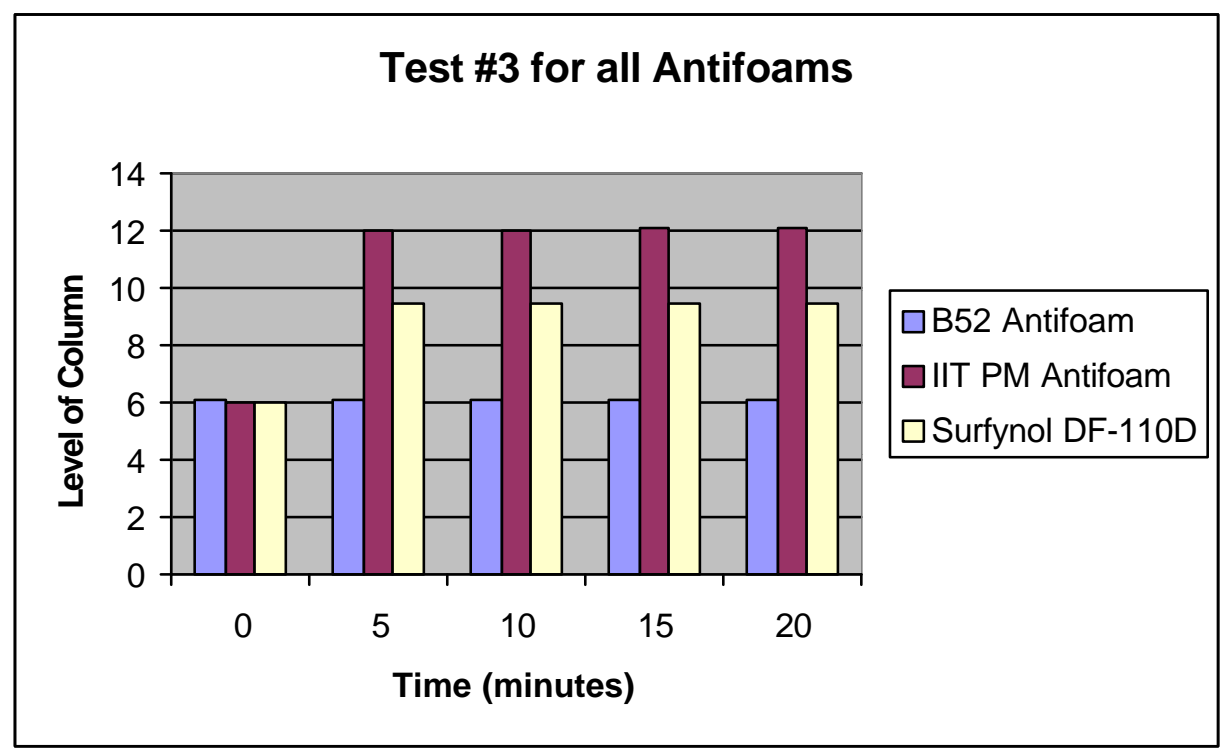

Figure 17 Large Foam Column Test \#3

\subsubsection{Antifoam Effectiveness During Testing}

The IITB52 antifoam used for all IIT and SRTC testing came from Lot\#1 of antifoam (IITB52-06-09-2000). Testing was completed by SRTC in an attempt to duplicate the results 
of the IIT foam column testing. This testing failed to identify B52 as the best antifoamer or defoamer in the testing of IITB52, IITPM and SurfynolDF-110D. Subsequent testing by IIT determined that the antifoam used by SRTC had degraded dramatically and was no longer effective. A new shipment of the Lot\#1 antifoam was received by SRTC on 9-25-2000 and this antifoam is identified as IITB52-09-25-2000. The foam column testing was completed with IITB52-09-25-2000 antifoam solution and IITB52 was the best antifoamer and defoamer tested. The SRTC Lot\#1 B52 antifoam was shipped back to IIT and IIT confirmed that its effectiveness was very low, $<10 \%$ that of the original Lot\#1 B52 antifoam tested at IIT.

The reason for the degradation of the antifoam is not known. The sample was shipped from IIT to SRTC in June so high temperatures could have led to degradation. In addition, the sample was used for three months by various researchers. When samples were removed from the bottle, a clean pipette tip was used and the bottle was only left open as long as necessary to remove the sample. Evaporation of the solvent is likely if the cap is left off the antifoam container but only the solvent would have evaporated so the antifoam would still be effective, although it would be more viscous.

Lot\#2 of antifoam solution was received by IIT in July 2000 (IITB52-07-31-2000) . The first shipment of Lot\#2 was used only by ORNL for their 20L antifoam test in August 2000 and the catalyst test in October 2000. A second shipment of Lot\#2 was sent to ORNL but has not been used (IITB52-07-31-2000) . Lot\#2 was made by a different manufacturer and was approximately $25 \%$ of the effectiveness of the Lot\#1 antifoam solution.

Lot\#3 of IITB52 antifoam solution was purchased by IIT from the Lot\#1 manufacturer. This shipment is approximately equal in effectiveness to the original Lot\#1. This antifoam lot will be identified by IITB52-10-05-2000. A shipment of $250 \mathrm{ml}$ from Lot\#3 was also sent to ORNL for their future testing. It is recommended that the IITB52-10-05-2000 lot of antifoam solution be used for subsequent ORNL testing and that the IITB52-07-31-2000 lot of antifoam be returned to SRTC.

SRTC or IIT will test all antifoam solutions prior to use. A draft antifoam testing procedure is included in Appendix A. 
WSRC-TR-2000-00261, REVISION 0

\subsection{SOLUBILITY STUDY OF CANDIDATE ANTIFOAM/DEFOAM AGENTS}

Solubility testing of the three candidate agents: Air Products Surfynol ${ }^{\circledR}$ DF-110D and IIT's IIT B52 and PM antifoam were performed. These three materials were tested for solubility in a 4.7 M Na salt solution.

The tests were conducted by placing $5 \mathrm{~mL}$ of our $9.4 \mathrm{M}$ Na Stock Salt Solution (see Table 1) via a $1.0 \mathrm{~mL}$ calibrated pipette into a $30 \mathrm{~mL}$ glass vial and adding $5 \mathrm{~mL}$ of DI water to the vial thus producing $10 \mathrm{~mL}$ of $4.7 \mathrm{M} \mathrm{Na}$ Salt Solution (this simulates the incoming salt solution to the STTPB process). Varying amounts of antifoam/defoam agent were added to these vials via $10 \mu \mathrm{L}$ and $0.1 \mathrm{~mL}$ calibrated pipettes to produce the desired concentrations of 1,000 ppmV, 2,000 ppmV, 3,000 ppmV and 10,000 ppmV. Solubility was determined by visual observations. The results of the study are summarized in Table 2. 
Table 3 Solubility of Candidate Antifoams/Defoams

\begin{tabular}{|l|c|c|c|c|l|}
\hline $\begin{array}{c}\text { Antifoam/Defoam } \\
\text { Agent }\end{array}$ & $\begin{array}{c}\mathbf{9 . 4} \text { M } \\
\mathbf{N a} \\
(\mathbf{m L})\end{array}$ & $\begin{array}{c}\text { DI } \\
\text { Water } \\
(\mathbf{m L})\end{array}$ & $\begin{array}{c}\text { Antifoam } \\
\text { Vol. } \\
(\mathbf{m L})\end{array}$ & $\begin{array}{c}\text { Antifoam } \\
\mathbf{C o n c} \\
\mathbf{( p p m V} \text { ) }\end{array}$ & Comments \\
\hline Blank & 5 & 5 & NONE & NA & Clear Solution \\
\hline IIT B52 & 5 & 5 & 0.01 & 1,000 & $\begin{array}{l}\text { Soluble, Slightly } \\
\text { Cloudy }\end{array}$ \\
\hline IIT B52 & 5 & 5 & 0.02 & 2,000 & $\begin{array}{l}\text { Soluble, Slightly } \\
\text { Cloudy }\end{array}$ \\
\hline IIT B52 & 5 & 5 & 0.03 & 3,000 & $\begin{array}{l}\text { A Few Small } \\
\text { Insoluble Drops }\end{array}$ \\
\hline IIT B52 & 5 & 5 & 0.1 & 10,000 & $\begin{array}{l}\text { Insoluble, Visible } \\
\text { Undissolved } \\
\text { Material }\end{array}$ \\
\hline IIT PM & 5 & 5 & 0.01 & 1,000 & $\begin{array}{l}\text { Soluble, Slightly } \\
\text { Cloudy }\end{array}$ \\
\hline IIT PM & 5 & 5 & 0.02 & 2,000 & $\begin{array}{l}\text { Soluble, Slightly } \\
\text { Cloudy }\end{array}$ \\
\hline IIT PM & 5 & 5 & 0.03 & 3,000 & $\begin{array}{l}\text { Soluble, Slightly } \\
\text { Cloudy }\end{array}$ \\
\hline IIT PM & 5 & 5 & 0.1 & 10,000 & $\begin{array}{l}\text { A Few Small } \\
\text { Insoluble Drops }\end{array}$ \\
\hline Surfynol DF-110D & 5 & 5 & 0.01 & 1,000 & $\begin{array}{l}\text { Insoluble, } \\
\text { Floating Globs }\end{array}$ \\
\hline Surfynol DF-110D & 5 & 5 & 0.02 & 2,000 & $\begin{array}{l}\text { Insoluble, } \\
\text { Floating Globs }\end{array}$ \\
\hline Surfynol DF-110D & 5 & 5 & 0.03 & 3,000 & $\begin{array}{l}\text { Insoluble, } \\
\text { Floating Globs }\end{array}$ \\
\hline Surfynol DF-110D & 5 & 5 & 0.1 & 10,000 & $\begin{array}{l}\text { Insoluble, } \\
\text { Floating Globs }\end{array}$ \\
\hline
\end{tabular}

\subsection{CONCLUSIONS}

If air entrainment in the slurry is carefully avoided, little or no foam will be generated during normal operations during precipitation, concentration, and washing of the precipitate.

Three candidate antifoam/defoam agents were tested on a laboratory scale with simulated KTPB slurry using the proposed STTPB process precipitation, concentration and washing steps. In all cases little or no foam formed during normal operations of precipitation, concentration and washing. Foam was produced by purposely-introducing gas sub-surface into the slurry. Once produced, the IIT B52 antifoam was effective in defoaming the slurry. In separate foam column tests, all antifoam/defoam agents were effective in mitigating foam formation and in defoaming a foamed $10 \mathrm{wt} \%$ insoluble solids slurry. Based on the results in 
this report as well as foam column studies at IIT, it is recommended that IIT B52 antifoam at the $1000 \mathrm{ppmV}$ level be used in subsequent STTPB work where foaming is a concern ${ }^{7}$.

During the concentration cycle the TPB solids are concentrated from about $0.6 \mathrm{wt} \%$ to 10 wt $\%$ by drawing off aqueous (permeate) through the cross-flow filter. During this process the antifoam level can vary greatly from greater than $3000 \mathrm{ppmV}$ if antifoam is totally insoluble to about $200 \mathrm{ppmV}$ if antifoam is totally soluble. Similarly, in the washing cycle the antifoam concentration could range from a few hundred ppmV to over $3000 \mathrm{ppmV}$. However, if one adds extra antifoam and over compensates for solubility the antifoam level could be in excess of $10,000 \mathrm{ppmV}$. This uncertainty in solubility and degradation suggests further work in this area.

This study indicates that the addition of antifoam agent hinders the recovery of NaTPB during washing. Washing precipitate with no antifoam agent added had the highest level of NaTPB recovery, but had the shortest overall washing time ( 19 hours) compared to $26-28$ hours for antifoam runs.

The solubilities of the three candidate antifoam/defoam agents were measured in a $4.7 \mathrm{M}$ sodium salt solution. The Surfynol DF-110D defoamer was essentially insoluble while the two IIT antifoamers; Particle Modifier (PM) and B52 were soluble to at least the $2000 \mathrm{ppmV}$ level.

\subsection{FUTURE WORK}

This study did not have the time or resources to investigate the optimal concentration of antifoam necessary to effectively mitigate foaming in each of the normal operational steps. Degradation of the antifoam in a high caustic environment was also lacking in this study. For actual waste, effects of radiation on the antifoam and its effectiveness are necessary as well as a study of the effects of the antifoam and its degradation products on downstream processing and glass quality. Due to the observed decrease in washing efficiency with antifoam a more detailed study of the washing effectiveness as a function of antifoam concentrated is warranted. 


\subsection{REFERENCES}

${ }^{1}$ D. P. Lambert, "Final Report: Illinois Institute of Technology Antifoam Recommendation to SRTC", WSRC-TR-2000-00297, Revision 0, 2000.

${ }^{2}$ R. A. Dimenna, et. al., Bases, "Assumptions, and Results of the Flowsheet Calculations for the Decision Phase Salt Disposition Alternatives", WSRC-RP-99-00006 Revision 0 1999.

${ }^{3}$ R. A. Peterson and J. O. Burgess, "The Demonstration of Continuous Stirred Tank Reactor Operations with High Level waste", WSRC-TR-99-00345, Revision 1, February 15, 2000.

${ }^{4}$ D. D. Lee and J. L. Collins, "Continuous-Flow Stirred-Tank Reactor 20-L Demonstration Test: Final Report, ORNL/TM-1999/234.

${ }^{5}$ Personal Communication with Dr. Mike Poirier of WRSC, June 5, 2000.

${ }^{6}$ Personal communication with Dr. Alex D. Nikolov of IIT, May 30, 2000.

${ }^{7}$ D. P. Lambert, M. A. Baich and P. R. Monson, "SRTC Interim Antifoam Recommendation", SRT-PTD-2000-00033, Revision 1, August 7, 2000.

\section{ACKNOWLEDGEMENTS}

The authors wish to acknowledge the following individuals who contributed to the program: Ike Hickson for performing all of the large column foam column testing, Gary Dobos and Curt Sexton of the SRTC Glassblowing shop who helped design and constructed the CSTR vessels. Summer Co-Op's Chris Cosper and Daniel Pittman who put together the experimental apparatus and did the initial water runs. Sammie King, Vicki Williams and Mary Moss who prepared simulants and provided outstanding experimental support. Stacie Owens who kept the digital cameras in operating condition, downloaded, and organized the many pictures taken. Jeff Siler provided his expertise is digital imaging and videotaping of the foam column tests. These experiments could not have been successfully completed with the unending support of Frances Williams supporting us in so many ways.

Page 34 of 34 
WSRC-TR-2000-00261, Revision 0

TECHNICAL REFERENCE

Manual:

L27

ITS/TNX PROCEDURE MANUAL

ANTIFOAM AGENT PERFORMANCE

Procedure:

2.19, $\operatorname{Rev} 0$

EVALUATION FOR SMALL TANK KTPB

PROCESS

DRAFT

Effective Date:

Page:

1 of 7

\section{APPENDIX A}

\section{ANTIFOAM AGENT PERFORMANCE EVALUATION FOR SMALL TANK KTPB PROCESS}

Approvals:

ITS Manager

Date

1.0 PURPOSE

The purpose of this procedure is to provide instructions for determining the acceptability of candidate antifoam agents for the Small Tank Tetraphenylborate (KTPB) Process.

2.0 SCOPE

This procedure covers the operation of a glass foam column with sintered glass frit to test the antifoam and defoaming capabilities of candidate antifoam agents.

\subsection{GENERAL INFORMATION}

This procedure describes the methodology to determine if a candidate antifoam agent is acceptable for use in the Small Tank Tetraphenylborate Process. The procedure enables determining both the antifoam capability as well as the defoaming capability of candidate antifoam agents. The antifoam capability is determined by charging $200 \mathrm{~mL}$ of a tetraphenylborate slurry containing a specified concentration of the antifoam agent into a 2.5-inch diameter glass column containing a glass frit rated at an average pore size of 10 to 15 microns. The slurry is then sparged at a nitrogen sparge rate of 0.5 Liters/min and the foam height measured as a function of time.

The defoaming capability of the candidate antifoam agent is determined by charging the column with $200 \mathrm{~mL}$ of tetraphenylborate slurry that contains no antifoam agent. The slurry is sparged at $0.5 \mathrm{Liters} / \mathrm{min}$ with nitrogen and the foam height measured as a function of time. When the foam height has reached steady state, the candidate antifoam agent is added onto the top of the foam. Again, the foam height is measured as a function of time.

\subsection{PRECAUSTIONS/LIMITATIONS}

\subsection{Testing Responsibilities}


WSRC-TR-2000-00261, Revision 0

TECHNICAL REFERENCE

Manual:

L27

ITS/TNX PROCEDURE MANUAL

\section{ANTIFOAM AGENT PERFORMANCE EVALUATION FOR SMALL TANK KTPB PROCESS}

\author{
Procedure: \\ Effective Date: \\ Page:
}

2.19, $\operatorname{Rev} 0$

2 of 7

Immobilization Technology Section (ITS) researchers will have the primary responsibility for the operation of this system. Operating limits and conditions not specified within this procedure or the Run Plan are at the discretion of the ITS researcher.

\subsection{Safety}

There are several hazards associated with these tests including broken glass, exposure to carcinogens (e.g. benzene), exposure to toxic substances (e.g. benzene, acetone, and methanol) and flammable atmospheres (e.g. benzene). Minimum personal protective equipment (PPE) includes lab coat, safety glasses with side shields and gloves. All testing is to be carried out in a ventilated hood.

Personnel executing this procedure shall be familiar with the appropriate material and safety data sheets.

Personnel should be familiar with the Job Hazards Analysis that was performed on this procedure.

Use of methanol and acetone for decontaminating the glass column between tests create a F Listed waste. All personnel must be familiar with the proper procedures for disposing of these wastes.

No oxidizing acids (e.g. nitric acid) should be in the proximity when executing this procedure.

\subsection{PREREQUISITE ACTIONS}

- Run plan has been approved prior to beginning a run.

- MKS Controller is on.

- Laboratory notebook is at location.

- Pressure Regulator is set at 80-100 psig. If not, contact Technical Lead.

- Laboratory Supervisor has been notified as to when testing will take place.

- Sufficient precipitate \& antifoam agent are available to complete the Run Plan and the shelf life of the antifoam agent has not expired.

- Test equipment as shown in Figure 1 has been setup in a ventilated hood.

- Nitrogen content of the compressed gas cylinder is sufficient to complete the Run Plan.

\subsection{PERFORMANCE}

This procedure will be used in conjunction with the Run Plan to control the test. Unusual conditions are to be reported immediately to the researcher or the laboratory supervisor. 
WSRC-TR-2000-00261, Revision 0

TECHNICAL REFERENCE

Manual:

L27

ITS/TNX PROCEDURE MANUAL

ANTIFOAM AGENT PERFORMANCE
EVALUATION FOR SMALL TANK KTPB
PROCESS

Procedure:

2.19, Rev 0

Effective Date:

Page:

3 of 7

\subsection{Column Preparation}

6.1.1 If the test column has not been cleaned since the last test, prepare test column per Attachment I.

\subsection{Test for Antifoam Capability}

During a 1 hour sparge period of $200 \mathrm{~mL}$ of $9-11$ wt \% unwashed KTPB slurry containing $1000 \mathrm{ppm}$ (by volume) of the candidate agent antifoam, the foam height must not exceed $10 \mathrm{vol}$. \% of the volume of the initial test slurry.

6.2.1 TRANSFER $250 \mathrm{~mL}$ of well-agitated unwashed 9-11 wt \% TPB slurry to a beaker.

6.2.2 CALCULATE the quantity of antifoam for an antifoam concentration in the $250-\mathrm{mL}$ of test slurry of $1000 \mathrm{ppm}$ (by volume).

Vol. $\mathrm{mL}$.

6.2.3 DILUTE the quantity determined in Step 6.2 .2 by a dilution factor of $5: 1$ using DI water.

6.2.4 ADD the diluted antifoam to the $250-\mathrm{mL}$ of test slurry.

6.2.5 MIX for a minimum period of 2 minutes.

6.2.6 TRANSFER the test slurry into the column until the slurry level is at the mark on the column equivalent to $200 \mathrm{~mL}$.

Column graduation mark at height of test slurry

6.2.7 INITIATE $\mathrm{N}_{2}$ sparge flow at $0.5 \mathrm{Liters} / \mathrm{min}$.

Time $\mathrm{N}_{2}$ sparge initiated

6.2.8 MAINTAIN the sparge for a minimum of 1 hours, RECORDING the column graduation at the top of the foam every 10 minutes.

$10 \min$

$20 \mathrm{~min}$

$30 \mathrm{~min}$

$40 \mathrm{~min}$

$50 \mathrm{~min}$

$60 \mathrm{~min}$

6.2.9 CALCULATE volume \% foam after 1 hour sparge

$\%$ Foam $=[($ Col Vol, $\mathrm{mL}$, Corresponding to 1-hr Reading)-(Initial Slurry Volume, $\mathrm{mL}](100)$

Initial Slurry Volume, $\mathrm{mL}$ 
WSRC-TR-2000-00261, Revision 0

TECHNICAL REFERENCE

Manual:

L27

ITS/TNX PROCEDURE MANUAL

ANTIFOAM AGENT PERFORMANCE
EVALUATION FOR SMALL TANK KTPB
PROCESS

Procedure:

2.19, $\operatorname{Rev} 0$

Effective Date:

Page:

4 of 7

$=$

Acceptable (<10\%): No

Yes Test Analyst Initials

IF acceptable, CONTINUE with Step 6.2.9. IF unacceptable, CONSULT with researcher as to the path forward.

6.2.10 DE-INVENTORY test column.

6.2.11 DECONTAMINATE column per procedure in Attachment I.

6.2.12 REPEAT Steps 6.2.1 through 6.2.11 above using washed, 9-11 wt \% test slurry.

$10 \mathrm{~min}$

$20 \mathrm{~min}$

$30 \mathrm{~min}$

$40 \mathrm{~min}$

$50 \mathrm{~min}$

$60 \min$

6.2.13 CALCULATE volume \% foam after 1 hour sparge

$\%$ Foam $=[($ Col Vol, $\mathrm{mL}$, Corresponding to 1-hr Reading)-(Initial Slurry Volume, $\mathrm{mL})](100)$ Initial Slurry Volume, $\mathrm{mL}$

$=$

Acceptable (<10\%): No___ Yes__ Test Analyst Initials

6.2.14 IF acceptable, PROCEED to testing for defoaming capability. IF unacceptable, CONSULT with researcher as to the path toward.

\subsection{Test for Defoaming Capability}

The addition of the equivalent to 1000-ppm antifoam to the generated foam reduces foam volume to $<10 \%$ of the initial test slurry volume and remains as such during 1 hour of sparging.

6.3.1 ADD $200 \mathrm{~mL}$ of $9-11$ wt $\%$ unwashed slurry to the test column.

Column graduation mark at height of test slurry

6.3.2 CALCULATE the quantity of antifoam required for an antifoam concentration in the $200-\mathrm{mL}$ of test slurry of $1000 \mathrm{ppm}$ (by volume). 
WSRC-TR-2000-00261, Revision 0

TECHNICAL REFERENCE

Manual:

L27

ITS/TNX PROCEDURE MANUAL

ANTIFOAM AGENT PERFORMANCE
EVALUATION FOR SMALL TANK KTPB
PROCESS

Procedure:

2.19, $\operatorname{Rev} 0$

Effective Date:

Page:

5 of 7

Vol. $\mathrm{mL}$.

6.3.3 DILUTE the quantity of antifoam calculated in step 2 by a factor of $5: 1$ using DI water.

6.3.4 INITIATE the $\mathrm{N}_{2}$ sparge flow at $0.5 \mathrm{Liters} / \mathrm{min}$.

Time $\mathrm{N}_{2}$ sparge is initiated

6.3.5 RECORD the column graduation at the top of the foam when steady state is reached.

Column graduation mark at the top of foam

6.3.6 ADD the antifoam prepared in Step 3 onto the top of the foam.

Time of addition

6.3.7 RECORD time and foam height when a new steady state foam height is reached.

Time

Column Graduation at Top of Foam

6.3.8 CONTINUE sparging for 1 hour recording column graduation mark at top of foam every 30 minutes.

$10 \mathrm{~min}$

$20 \mathrm{~min}$

$30 \mathrm{~min}$

$40 \mathrm{~min}$

$50 \mathrm{~min}$

$60 \mathrm{~min}$

6.3.9 CALCULATE volume \% foam after 1 hour sparge

$\%$ Foam $=[($ Col Vol., $\mathrm{mL}$, Corresponding to 1-hr Reading) - (Initial Slurry Volume, $\mathrm{mL})](100)$ Initial Slurry Volume, $\mathrm{mL}$

$=$

Acceptable (<10\%): No___ Yes__ Test Analyst Initials

6.3.10 DE-INVENTORY column. 
WSRC-TR-2000-00261, Revision 0

TECHNICAL REFERENCE

Manual:

L27

ITS/TNX PROCEDURE MANUAL

ANTIFOAM AGENT PERFORMANCE

EVALUATION FOR SMALL TANK KTPB

PROCESS

DRAFT

Procedure:

2.19, $\operatorname{Rev} 0$

Effective Date:

Page:

6 of 7

\subsubsection{DECONTAMINATE column per Attachment I}

7.0 RECORDS

No Records

8.0 REFERENCES

9.0 ATTACHMENTS

I. Procedure for Decontaminating Foam Test Column 
WSRC-TR-2000-00261, Revision 0

TECHNICAL REFERENCE

Manual:

L27

ITS/TNX PROCEDURE MANUAL

ANTIFOAM AGENT PERFORMANCE EVALUATION FOR SMALL TANK KTPB PROCESS
DRAFT
Procedure:

Effective Date:

Page:
2.19, $\operatorname{Rev} 0$

7 of 7

FIGURE 1

ANTIFOAM TEST COLUMN CONFIGURATION

Test Slurry

Delivery

System

Tubing (used only to transfer test slurry into column - removed during test)
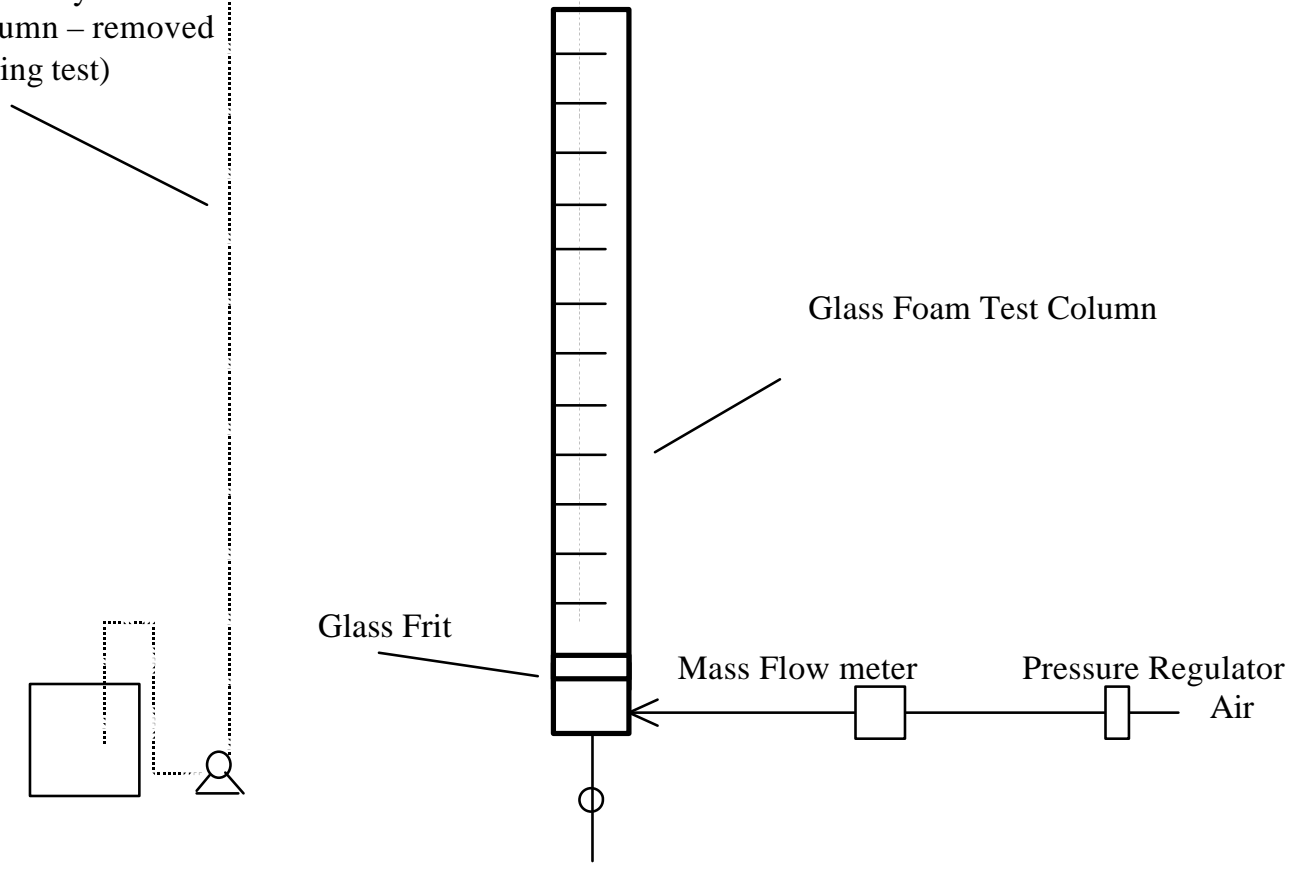

Attachment I

Page A-7 of 7 
WSRC-TR-2000-00261, Revision 0

TECHNICAL REFERENCE

Manual:

L27

ITS/TNX PROCEDURE MANUAL

\section{ANTIFOAM AGENT PERFORMANCE EVALUATION FOR SMALL TANK KTPB PROCESS}

\author{
Procedure: \\ Effective Date: \\ Page:
}

2.19, $\operatorname{Rev} 0$

8 of 7

\section{PROCEDURE FOR \\ DECONTAMINATING THE FOAM TEST COLUMN}

Safety

1. Wear PPE when handling cleaning solutions. This includes at the minimum safety glasses, rubber gloves, and labcoat

2. Make certain that no oxidizing acids $\left(\right.$ e.g. $\left.\mathrm{HNO}_{3}\right)$ are used in this procedure.

\section{Cleaning Procedure}

1. De-inventory the column by placing new tubing into the column and pump out the solution into a small carboy.

2. Prepare to clean the column.

3. First, rinse the column with $200-\mathrm{mL}$ DI water. Then dispose the DI water into an appropriate organic rinse container.

4. Next, pour $200 \mathrm{~mL}$ of methanol into the portion of column above the sintered glass frit as well as $20 \mathrm{~mL}$ below the sintered glass frit.

5. Sparge the methanol above and below the sintered glass frit for about 10 minutes each.

6. Turn off sparge. Take the column off the racks and place a rubber stopper on top of the column.

7. Shake the column manually for several minutes. This ensures that no antifoam is left on the sides of the column.

8. Take column to the organic rinse carboy and drain the column.

9. Next, rinse the column with DI water and dispose it into the organic rinse carboy.

10. Pour $200 \mathrm{~mL}$ of acetone into the portion of column above the sintered glass frit as well as $20 \mathrm{~mL}$ below the sintered glass frit.

11. Sparge the acetone above and below the sintered glass frit for about 10 minutes each.

12. Turn off the sparge. Take the column off the racks and place a rubber stopper on top of the column.

13. Shake the column manually for several minutes. This ensures that no antifoam or methanol is left on the sides of the column.

14. Take the column to the organic rinse carboy and drain the column.

15. Pour $200 \mathrm{~mL}$ of DI water into the portion of column above the sintered glass frit as well as $20 \mathrm{~mL}$ below the sintered glass frit.

16. Sparge the DI water above and below the sintered glass frit for about 10 minutes each.

17. Turn off the sparge. Take the column off the racks and place a rubber stopper on top of the column.

18. Shake the column manually for several minutes. This ensures that no methanol or acetone is left on the sides of the column.

19. Drain DI water into organic rinse container and let the column air dry.

20. Steps 1-19 are to be conducted between every antifoam test. 


\section{Distribution:}

E. W. Holtzscheiter, 773-A

W. L. Tamosaitis, 773-A

L. F. Landon, 704-1T

S. L. Mara, 704-1T

J. T. Carter, 704-3N

K. J. Rueter, 704-3N

S. D. Fink, 773-A

P. L. Rutland, 704-196N

R. C. Fowler, 704-196N

R. A. Peterson, 773-A

M. J. Barnes, 773-A

D. D. Walker, 773-A

M. R. Poirier, 773-42A

P. C. Suggs, 704-196N

M. G. Schwenker, 703-46A

J. M. Reynolds, 704-S

J. W. McCullough, 704-3N

H. D. Harmon, 704-3N

S. N. Schlahta, 704-196N

J. F. Walker, ORNL

T. T. Kent, ORNL

D. D. Lee, ORNL

R. E. Eibling, 704-1T

I. Hickson, III, 704-1T

A. D. Nikolov, IIT

D. T. Wasan, IIT

STI 703-43A (4) 